


\section{Berekening van een onzekerheidsmarge voor fijnstof reducerende technieken bemeten op één in plaats van twee bedrijfslocaties}

A. Winkel, N.W.M. Ogink 
Winkel, A., N.W.M. Ogink, 2020. Berekening van een onzekerheidsmarge voor fijnstof reducerende technieken bemeten bij één in plaats van twee bedrijfslocaties. Wageningen Livestock Research, Rapport 1239.

Dit rapport is gratis te downloaden op https://doi.org/10.18174/524760 of op www.wur.nl/livestock-research (onder Wageningen Livestock Research publicaties).

(C) 2020 Wageningen Livestock Research

Postbus 338, 6700 AH Wageningen, T 03174839 53, E info.livestockresearch@wur.nl, www.wur.nl/livestock-research. Wageningen Livestock Research is onderdeel van Wageningen University \& Research.

Wageningen Livestock Research aanvaardt geen aansprakelijkheid voor eventuele schade voortvloeiend uit het gebruik van de resultaten van dit onderzoek of de toepassing van de adviezen.

Alle rechten voorbehouden. Niets uit deze uitgave mag worden vermenigvuldigd en/of openbaar gemaakt worden door middel van druk, fotokopie, microfilm of op welke wijze dan ook zonder voorafgaande toestemming van de uitgever of auteur.

Wageningen Livestock Research is NEN-EN-ISO 9001:2015 gecertificeerd. Op al onze onderzoeksopdrachten zijn de Algemene Voorwaarden van de Animal Sciences Group van toepassing. Deze zijn gedeponeerd bij de Arrondissementsrechtbank Zwolle.

Wageningen Livestock Research Rapport 1239 


\section{Inhoud}

$\begin{array}{ll}\text { Samenvatting } & 5\end{array}$

1 $\begin{array}{ll}\text { Inleiding } & \mathbf{7}\end{array}$

$\begin{array}{lll}1.1 & \text { Context en aanleiding } & 7\end{array}$

1.2 Doel $\quad 8$

$\begin{array}{lll}1.3 & \text { Opzet rapport } & 9\end{array}$

Theoretisch kader en eerdere analyses van variatiebronnen en onzekerheid 10

$\begin{array}{lll}2.1 & \text { Emissiefactoren in toetsingskaders } & 10\end{array}$

2.2 Tussenbedrijfsvariatie en binnenbedrijfsvariatie $\quad 10$

2.3 Onzekerheid van gemeten emissies en reducties 10

2.4 Eerdere analyses van variatiebronnen en onzekerheid $\quad 12$

2.4.1 Geuremissiefactoren bij vleesvarkens en zeugen (Ogink et al., 1997) 12

2.4.2 Ammoniakemissiefactoren varkenscategorieën (Mosquera et al., 2008) 13

2.4.3 Ammoniakemissiefactor melkvee Rav A 1.100 (Ogink et al., 2014) 13

2.4.4 Fijnstofemissiefactoren (Winkel et al., 2015) 14

2.5 Betekenis variatiebronnen voor meetprotocollen $\quad 14$

$3 \quad$ Keuze en berekeningswijze onzekerheidsmarge $\quad 15$

3.1 Keuze voor een type onzekerheidsmarge $\quad 15$

3.2 Berekeningswijze gekozen type onzekerheidsmarge 16

$4 \quad$ Resultaten en discussie $\quad 17$

$4.1 \quad$ Onzekerheid bij technieken bemeten bij meerdere bedrijfslocaties $\quad 17$

4.2 Tussenbedrijfsverschillen en onzekerheidsmarge $\quad 18$

4.3 Toetsing bedrijfseffect op reductiepercentage techniek 23

4.4 Wenselijkheid meetcampagnes aan één bedrijfslocatie 24

$\begin{array}{lll}4.5 & \text { Tussenbedrijfsvariatie i.r.t. bedrijfsemissiemonitoring } & 25\end{array}$ 



\section{Samenvatting}

Technieken voor het reduceren van de fijnstofemissie uit stallen worden in Nederland opgenomen in regelgeving nadat de reducties zijn doorgemeten op twee veehouderijen waarbij op elke bedrijfslocatie zes 24-uursmetingen worden verricht, gespreid over het jaar (eens per twee maanden) en de productieperiode van de dieren. Tussen 2017 en 2020 zijn er in de Gelderse Vallei regio zogenaamde "fijnstofpilots" verricht in het kader van het "Manifest Gezonde Leefomgeving Veehouderij". In deze pilots werden fijnstof reducerende technieken bemeten op één bedrijfslocatie en met vereenvoudigde maar wetenschappelijk valide meetmethoden zodat deze relatief goedkoop en snel beschikbaar zouden kunnen komen om de fijnstofbelasting in het gebied door veehouderijbedrijven te kunnen verminderen. In deze deskstudie is in opdracht van het Ministerie van Infrastructuur en Waterstaat berekend welke extra onzekerheid ontstaat wanneer een techniek wordt bemeten bij één in plaats van twee bedrijfslocaties. Deze onzekerheid kan worden benut om dergelijke technieken op te nemen in de officiële "Lijst Emissiefactoren fijnstof voor veehouderij" behorende bij de Regeling beoordeling luchtkwaliteit (Rbl) met een bijgesteld reductiepercentage bestaande uit de gemiddelde gemeten reductie minus een onzekerheidsmarge gelijk aan de berekende extra onzekerheid. Wordt een techniek later op een tweede bedrijfslocatie bemeten, dan kan het bijgestelde reductiepercentage worden vervangen door definitief reductiepercentage: het gemiddelde van de twee datasets.

In deze deskstudie is in hoofdstuk 2 een samenvatting gegeven van de rol van emissiefactoren en reductiepercentages in toetsingskaders voor veehouderijbedrijven, de kennis omtrent statistische onzekerheid bij voornoemde cijfers, de uitkomsten van eerdere onzekerheidsstudies t.a.v. ammoniaken geuremissie uit huisvestingssystemen, en de betekenis van dit alles voor de inrichting van meetprotocollen zoals die in Nederland en VERA worden gehanteerd.

Vervolgens is gestart met het aan de hand van datasets van 11 in het verleden bemeten fijnstof reducerende technieken berekenen van de onzekerheid die geaccepteerd wordt door reductiepercentages te baseren op meetseries aan twee bedrijfslocaties (twee installaties). Uit deze berekeningen blijkt dat deze onzekerheid ook bij twee bedrijfslocaties in de meeste gevallen al groot is. Uitgedrukt als $95 \%$-betrouwbaarheidsinterval in absolute reductieprocenten varieert deze tussen het gemiddelde \pm 8 reductieprocenten en het gemiddelde \pm 202 reductieprocenten. In de tweede plaats blijkt uit voornoemde datasets dat vergelijkbare/identieke technische installaties, geïnstalleerd op verschillende bedrijfslocaties, bij de meerderheid van de technieken (7 van de 10) statistisch significante verschillen in prestaties tussen de bedrijven laten zien, variërend tussen 2 en 32 procentpunten reductie.

In de derde plaats is berekend welke extra onzekerheid in het reductiepercentage ontstaat wanneer een techniek (voorlopig) wordt bemeten bij één bedrijfslocatie. Hieruit wordt een onzekerheidsmarge (aftrek) geadviseerd van 10 absolute procentpunten reductie. Op basis van de analyse van de datasets kan geen verbijzondering worden aangebracht naar aparte onzekerheidsmarges op grond van de plaats van de techniek in het stalsysteem (in de stal of end-of-pipe) of het werkingsprincipe van de techniek.

Samengevat hebben de fijnstofpilots in de Gelderse Vallei, en in het verlengde daarvan deze deskstudie, het inzicht opgeleverd dat één-bedrijf-meetcampagnes t.a.v. verschillende aspecten een toegevoegde waarde kunnen hebben, maar tevens dat de multi-site-approach (2-4 bedrijfslocaties) zoals die in de meetprotocollen van Nederland en VERA wordt beschreven - het minimaal noodzakelijke is om een betrouwbaar en representatief reductiepercentage voor regelgeving te verkrijgen. Het gebruiken van de onzekerheidsmarge uit deze deskstudie zou naar het oordeel van de auteurs vanuit wetenschappelijk perspectief gezien moeten worden als tijdelijke maatregel; als tussenstap naar een eindcijfer. Aanbevolen wordt om technieken die perspectiefvol lijken uit éénbedrijf-meetcampagnes op tenminste een tweede bedrijfslocatie te bemeten. De ontwikkelingen rondom sensortechnologieën voor realtime bedrijfsemissiemonitoring bieden m.b.t. het voorgaande perspectief om de prestaties van emissiereducerende technieken vervolgens in de praktijk te managen en te waarborgen. 


\section{$1 \quad$ Inleiding}

\subsection{Context en aanleiding}

Technieken voor het reduceren van de fijnstofemissie uit stallen worden in Nederland met een reductiepercentage voor fijnstof $\left(\mathrm{PM}_{10}\right)$ opgenomen in de officiële "Lijst Emissiefactoren fijn stof voor veehouderij" (Rijksoverheid, 2019) behorende bij de Regeling beoordeling luchtkwaliteit (Rbl) nadat deze zijn doorgemeten volgens het "Protocol voor meting van fijnstofemissie uit huisvestingssystemen in de veehouderij 2010" (Ogink et al., 2011). In dit protocol worden voor luchtwassers reductiemetingen op twee bedrijfslocaties voorgeschreven. In de praktijk wordt dit ook toegepast op andere stofverwijderingstechnieken. Het protocol schrijft voor dat een fijnstof reducerende techniek op twee veehouderijen wordt toegepast waarbij op elke bedrijfslocatie de fijnstofreductie gedurende zes 24-uursperioden wordt gemeten, gespreid over het jaar (circa eens per twee maanden) en de productieperiode van de dieren. Met deze strategie worden 12 waarnemingen verkregen, met minimale autocorrelatie tussen de 24-uursmetingen op een bedrijf, en kan op het kleinst mogelijke niveau van één herhaling worden geverifieerd of de prestatie van een techniek op de eerste bedrijfslocatie reproduceerbaar is op een tweede bedrijfslocatie (met veelal verschillen in ras, huisvestingssysteem, bedrijfsmanagement, enzovoort). De fijnstof reducerende technieken die op dit moment zijn opgenomen in de categorieën E 7 (specifieke technieken voor fijnstofreductie) en E 6 (mestdroogtechnieken die ook fijnstof reduceren) zijn tussen 2007 en 2015 volgens voornoemde protocol bemeten.

De meetrapporten uit deze meetcampagnes zijn destijds aangeboden aan het Ministerie van Infrastructuur en Waterstaat (IenW) waarna de Minister besloot over de opname van technieken met hun reductiepercentage in de "Lijst Emissiefactoren fijn stof voor veehouderij": het "overzicht" zoals bedoeld in de Rbl, artikel 66, lid $\mathrm{i}^{1}$. Zoals beschreven in paragraaf 4.3 van de Rbl moet voor inrichtingen zoals veehouderijen de luchtkwaliteit rondom het bedrijf worden bepaald op basis van de emissiefactoren en reductiepercentages uit voornoemde Lijst in combinatie met een verspreidingsmodel conform het Nieuw Nationaal Model. Voor veehouderijen wordt daarvoor het ISL3a model gebruikt. De uitkomsten van het model worden getoetst aan de grenswaarden voor $\mathrm{PM}_{10}$ in de buitenlucht zoals die Europees zijn vastgelegd in EU Richtlijn 2008/50/EC en nationaal in paragraaf 4 van Bijlage 2 bij de Wet milieubeheer. Het drieluik van emissiefactoren/reductiepercentages, het verspreidingsmodel, en de grenswaarden vormen samen het toetsingskader voor fijnstof rond veehouderijen en moeten burgers beschermen tegen te hoge lokale fijnstofconcentraties in de buitenlucht.

Sinds december 2016 wordt in de Gelderse Vallei in het kader van het "Manifest Gezonde Leefomgeving Veehouderij" gestreefd naar het verminderen van buitenluchtconcentraties van fijnstof, geur en ammoniak t.g.v. de regionaal aanwezige veehouderijsector. Eén van de sporen van het Manifest is het uitvoeren van zogenaamde "fijnstofpilots" onder regie van het "Praktijkcentrum Emissiereductie Veehouderij" (PEV). Doel van deze pilots is het relatief snel, eenvoudig en goedkoop beproeven van innovatieve technieken voor fijnstofreductie om deze beschikbaar te laten komen voor veehouders om hun bijdrage aan regionale luchtverontreiniging te verminderen. Na een aanmeldperiode voor leveranciers van nieuwe oplossingen zijn alle aangemelde technieken beoordeeld op hun technische haalbaarheid en financiële betaalbaarheid en al dan niet geselecteerd door een selectiecommissie voor deelname in een pilot.

\footnotetext{
${ }^{1} \mathrm{Rbl}$, artikel 66, lid i luidt:

"Vóór 15 maart van ieder kalenderjaar maakt de Minister de volgende gegevens bekend: [...] een overzicht van de emissiefactoren per dier per jaar van zwevende deeltjes (PM10) en van de emissiereductiepercentages van zwevende deeltjes (PM10) van additionele technieken bij veehouderijen"
} 
In de pilots zijn de geselecteerde technieken ingebouwd in bestaande praktijkstallen met pluimvee en bemeten door Wageningen Livestock Research. Daarbij is voornoemde meetprotocol en meetstrategie zo veel mogelijk gevolgd, maar zijn ook bewust omissies aangebracht in het kader van snelheid, eenvoud en lage kosten. De belangrijkste omissie betrof het uitvoeren van metingen aan één i.p.v. twee bedrijfslocaties, daarmee resulterend in zes

i.p.v. 12 waarnemingen. Deze omissie betekent dat de werkelijke reductie van de techniek minder betrouwbaar wordt geschat omdat herhaling op het meest kleine niveau van één andere bedrijfslocatie (met veelal een ander ras, huisvestingssysteem en bedrijfsmanagement) ontbreekt. Bij ondertekening van het Manifest Gezonde Leefomgeving Veehouderij in december 2016 was het aanvankelijk de bedoeling om de effectieve technieken uit de pilots toe te staan bij vergunningsverlening aan veehouders via opname in een regionaal erkende Lijst.

Tijdens overleg tussen vertegenwoordigers van o.a. PEV, WLR en het Ministerie van IenW in september 2017 is door de laatste partij echter toegezegd dat meetrapporten uit de pilots mogen worden ingediend bij de Rijksdienst voor Ondernemend Nederland (RVO) zodat deze beoordeeld kunnen worden door leden van de Technische Adviseurs Pool (TAP) en - voorzien van een technisch advies - aangeboden kunnen worden aan de Minister van IenW. Deze laatste besluit vervolgens over opname van de techniek in de nationale Lijst Emissiefactoren fijn stof voor veehouderij behorende bij de Rbl.

Om rekening te houden met de omissie van het doormeten van een techniek op één i.p.v. twee bedrijfslocaties is aan WLR gevraagd een advies te geven over een op het bemeten reductiepercentage aan te houden onzekerheidsmarge. Perspectiefvolle technieken uit de pilots worden dan met een bijgesteld reductiepercentage opgenomen in voornoemde Lijst bestaande uit het bemeten reductiepercentage minus een onzekerheidsmarge t.g.v. het doormeten van de techniek op één i.p.v. twee bedrijfslocaties. Wordt een techniek later op een tweede bedrijfslocatie bemeten (waarmee de dataset tevens wordt vergroot van zes naar 12 waarnemingen), dan kan het bijgestelde reductiepercentage worden vervangen door een definitief reductiepercentage zijnde de overallgemiddelde reductie van bedrijfslocaties 1 en 2 . De onzekerheidsmarge kan dan komen te vervallen.

\subsection{Doel}

Het eerste doel van deze deskstudie was om aan de hand van datasets van in het verleden bemeten fijnstof reducerende technieken vast te stellen welke extra onzekerheid in het reductiepercentage ontstaat wanneer een techniek (voorlopig) wordt bemeten bij één bedrijfslocatie. Deze onzekerheid kan benut worden om dergelijke technieken op te nemen in de officiële "Lijst Emissiefactoren fijnstof voor veehouderij" behorende bij de Rbl met een bijgesteld reductiepercentage bestaande uit de gemiddelde gemeten reductie minus een onzekerheidsmarge gelijk aan de berekende extra onzekerheid.

Het tweede doel van deze deskstudie was om aan de hand van dezelfde datasets vast te stellen of de prestaties van fijnstof reducerende technieken statistisch significant verschillen tussen de (doorgaans) twee (soms 3 en 5) bedrijfslocaties per techniek. Deze analyse is bedoeld om meer inzicht te krijgen in welke mate de gemiddelde prestatie van een fijnstof reducerende techniek op een eerste bedrijfslocatie overeen komt met de gemiddelde prestatie op een volgende bedrijfslocatie. Op basis van deze analyse worden aanbevelingen gedaan over de wenselijkheid van één-locatie-meetcampagnes om tot een representatief en betrouwbaar reductiepercentage voor regelgeving te komen.

De berekening van de onzekerheidsmarge alsook het op basis van analyses uitwerken van aanbevelingen over hoe om te gaan met één-locatie-meetcampagnes in de toekomst zijn gedaan in opdracht van het Ministerie van Infrastructuur en Waterstaat. 


\subsection{Opzet rapport}

Dit rapport begint in hoofdstuk 2 met het beschrijven van het theoretisch kader met betrekking tot emissiefactoren en toetsingskaders, tussenbedrijfsvariatie en binnenbedrijfsvariatie, de onzekerheid rondom gemeten emissiereducties, een bespreking van eerdere studies met analyses van variatiebronnen en onzekerheid en de betekenis van variatiebronnen voor meetprotocollen. In hoofdstuk 3 wordt beschreven op welke manier de onzekerheidsmarge tot stand is gekomen. Hoofdstuk 4 geeft de resultaten van berekeningen van de onzekerheid en tussenbedrijfsverschillen in reductiepercentages voor 11 in de Lijst opgenomen fijnstof reducerende technieken. Op basis van de verkregen tussenbedrijfsverschillen wordt de onzekerheidsmarge voor technieken bemeten bij één bedrijfslocatie bepaald. Tot slot wordt in hoofdstuk 4 statistisch getoetst in welke mate de gemiddelde prestatie van een fijnstof reducerende techniek op een eerste bedrijfslocatie overeen komt met de gemiddelde prestatie op een volgende bedrijfslocatie De conclusies en aanbevelingen worden gegeven in hoofdstuk 5. 


\section{Theoretisch kader en eerdere analyses van variatiebronnen en onzekerheid}

\subsection{Emissiefactoren in toetsingskaders}

De toetsingskaders voor fijnstof, ammoniak en geur kennen - naast een verspreidingsmodel en grenswaarden - alle drie een "lijst" met emissiefactoren/reductiepercentages, gegroepeerd in diercategorieën en vervolgens onderverdeeld in huisvestingssystemen/reductietechnieken. Het gaat dan om respectievelijk: de Lijst Emissiefactoren fijn stof voor veehouderij; Bijlage 1 bij de Regeling ammoniak en veehouderij (Rav); en Bijlage 1 bij de Regeling geurhinder en veehouderij (Rgv). Alle lijsten volgen de codering van de Rav voor wat betreft diercategorieën en huisvestingssystemen. Afgezien van die emissiefactoren/reductiepercentages die afgeleid zijn van een andere diercategorie of reductietechniek, zijn de meeste emissiefactoren/reductiepercentages in het verleden bemeten aan werkelijke bedrijfslocaties en gerapporteerd in een meetrapport.

Een emissiefactor van een huisvestingssysteem of een reductiepercentage van een emissiereducerende techniek is een door metingen verkregen schatting van de werkelijke gemiddelde emissie of reductie. Deze laatste is onbekend. De werkelijke gemiddelde emissie of reductie zou in principe vastgesteld kunnen worden door alle in Nederland bestaande bedrijfslocaties met het huisvestingssysteem of reductietechniek aan metingen te onderwerpen, maar dit is uiteraard praktisch en financieel ondoenlijk. Om de werkelijke gemiddelde emissie of reductie zo dicht als redelijkerwijs mogelijk te benaderen bij een zo efficiënt mogelijke inzet van budget en meetapparatuur, zijn meetprotocollen opgesteld zoals die voor fijnstof (Ogink et al., 2011).

\subsection{Tussenbedrijfsvariatie en binnenbedrijfsvariatie}

Meetprotocollen schrijven voor dat een huisvestingssysteem bij vier bedrijfslocaties en een reductietechniek bij twee bedrijfslocaties wordt bemeten. Bij de laatste gaat het overigens om een case-control strategie, bijvoorbeeld door een stal met een reductietechniek uit te rusten (case) en een volledig identieke stal zonder reductietechniek (control) op dezelfde bedrijfslocatie en gelijktijdig als referentie te bemeten. Deze "multi-site approach" van vier respectievelijk twee bedrijfslocaties is nodig omdat er substantiële tussenbedrijfsvariatie kan bestaan. D.w.z. de emissie van een huisvestingssysteem of de reductie van een reductietechniek kan substantieel variëren tussen bedrijfslocaties met een identiek huisvestingssysteem of reductietechniek. Verder schrijven meetprotocollen voor dat een huisvestingssysteem of reductietechniek zes maal moet worden bemeten gedurende 24 uur, verspreid over het kalenderjaar en de productiecyclus van de dieren. Deze herhaalde metingen binnen één bedrijfslocatie zijn nodig omdat er substantiële

binnenbedrijfsvariatie kan bestaan. D.w.z. de emissie van een huisvestingssysteem of reductie van een reductietechniek kan substantieel variëren in de tijd t.g.v. van seizoenen/weersomstandigheden of door effecten gerelateerd aan het productiestadium van de dieren. Metingen in perioden van 24 uur zijn nodig omdat emissies (en vele gerelateerde variabelen op veehouderijbedrijven) een terugkerend patroon over de dag kennen.

\subsection{Onzekerheid van gemeten emissies en reducties}

De emissiefactor van een huisvestingssysteem of een reductiepercentage van een emissiereducerende techniek zoals die verkregen zijn door metingen volgens meetprotocollen kunnen zeer dicht bij de (onbekende) werkelijke emissie of reductie liggen, maar deze uiteraard ook onderschatten of 
overschatten. Met andere woorden: de door metingen verkregen emissie of reductie kennen een mate van onzekerheid. Op basis van het aantal bemeten bedrijven en de spreiding die aangetroffen is kan berekend worden met welke precisie de gemiddelde emissie of reductie is geschat. Dit kan worden uitgedrukt in een $x x \%$-betrouwbaarheidsinterval waarvan het $\mathbf{9 5 \%}$-betrouwbaarheidsinterval (95\%-BI) een wetenschappelijke standaard is. Het 95\%-BI bestaat uit een ondergrens en een bovengrens voor de door metingen verkregen gemiddelde emissie of reductie waarvoor geldt dat de kans $95 \%$ is dat de werkelijke emissie of reductie daarbinnen valt. Concreet betekent dit: wanneer er niet één maar 20 meetcampagnes uitgevoerd zouden worden volgens voornoemde multi-site approach dan zullen gemiddeld 19 meetcampagnes (95\%) een emissie of reductie opleveren die binnen het interval ligt terwijl er gemiddeld één meetcampagne $(5 \%)$ een emissie of reductie zal opleveren die buiten het interval ligt.

Het $95 \%-B I$ voor een gemiddelde gemeten emissie of reductie kan worden verkregen door de gemeten emissies of reducties als normale verdelingen te veronderstellen. Een normale verdeling is een verzameling van getallen die, wanneer die getallen worden geplot als frequentie op de $\mathrm{Y}$-as en de waarde op de $\mathrm{x}$-as, een symmetrische klokvorm geeft met het centrum van de klok rond het gemiddelde (die dan gelijk is aan de mediaan en modus) en "staarten" naar links en rechts. Emissiecijfers zijn echter veelal geclusterd rond lage niveaus met nu en dan hoge uitschieters: de verdeling is "links-scheef" (left-skewed; asymmetrisch) en dus vaak niet-normaal verdeeld. Reductiepercentages zijn aan de rechterzijde begrenst door het getal 100. Negatieve reducties (getallen beneden nul) kunnen voorkomen wanneer de emissie in een case-stal (mét emissiereducerende techniek) hoger was dan de emissie van een control-stal; naar links is er geen begrenzing. Wanneer de reductiepercentages bij de grenzen van nul en 100 vandaan liggen is het veronderstellen van normaliteit desondanks een voldoende valide en pragmatische veronderstelling. Als aan de eis van normaliteit niet voldaan wordt kunnen de natuurlijke logaritmen van de emissies of reducties worden genomen om mee verder te rekenen (zogenaamde log-transformatie). Een natuurlijke logaritme van een emissie- of reductiegetal is dat getal waarmee het getal van Euler ( $e=$ 2,718 ) moet worden verheven om tot het emissie- of reductiegetal te komen. Deze zijn doorgaans wel normaal verdeeld. Na het berekenen van een $95 \%-B I$ op logaritmische schaal kunnen ondergrens en bovengrens terug getransformeerd worden naar de originele schaal door de exponent te nemen van de grenzen. Doordat het $95 \%-B I$ op logaritmische schaal is berekend wordt op de originele schaal logischerwijze een scheef interval verkregen rond het gemiddelde (het gemiddelde ligt hierbij niet in het centrum van het interval).

Een 95\%-BI wordt als volgt berekend:

Gemiddelde $\pm t_{(\alpha ; v=n-1)} * S E$

met:

$t=$ waarde uit de Student's $t$ verdeling bij onbetrouwbaarheid $\alpha$ (bedraagt 0,05 voor een 95\%-BI) en $v$ vrijheidsgraden $(v=n-1)$;

$n=$ het aantal bemeten bedrijfslocaties (bedrijfsgemiddelden);

$S E=$ standard error (standaardfout) van het gemiddelde. Deze wordt berekend door de standaarddeviatie $(S D)$ te delen door de wortel uit het aantal bedrijfslocaties: $S D / \sqrt{n}$.

De $t$ waarde in de Student's $t$ tabel bij $\alpha=0,05$ bedraagt 12,706 bij 2 bedrijfslocaties $(v=1) ; 4,303$ bij 3 bedrijfslocaties $(v=2)$; en 3,182 bij 4 bedrijfslocaties $(v=3)$. De $t$ waarde neemt verder af tot 2,262 bij 10 bedrijfslocaties $(v=9) ; 2,093$ bij 20 bedrijfslocaties $(v=19) ; 2,045$ bij 30 bedrijfslocaties $(v=$ $29)$; en 1,960 bij een oneindig aantal bedrijfslocaties. Deze opsomming illustreert dat een toename van het aantal bedrijfslocaties onderin de range (van 2 naar 3, 4, 5, etcetera) tot een snel afnemende $t$ waarde leidt (en daarmee tot snel nauwer wordende 95\%-BI grenzen rond de bemeten gemiddelde emissie of reductie) om daarna af te vlakken naar het eindniveau van circa 1,96. 


\subsection{Eerdere analyses van variatiebronnen en onzekerheid}

\subsubsection{Geuremissiefactoren bij vleesvarkens en zeugen (Ogink et al., 1997)}

De eerste onzekerheidsberekeningen van emissiefactoren werden uitgevoerd voor geuremissiefactoren (uitgedrukt in: odour units/s per dierplaats) verkregen uit een omvangrijke meetcampagne in de jaren 1996-1999 bij 20 verschillende huisvestingssystemen voor varkens, pluimvee en rundvee (Ogink \& Lens, 2001). Om de nauwkeurigheid van het meetprotocol te kunnen beoordelen werden bij twee huisvestingssystemen vier bedrijfslocaties bemeten (bij de overige huisvestingssystemen was dit één bedrijfslocatie), namelijk de conventionele huisvesting voor vleesvarkens en zeugen. De data van deze twee huisvestingssystemen is geanalyseerd en gerapporteerd door Ogink et al. (1997).

De bemeten conventionele huisvesting voor vleesvarkens bestond uit hokken met $\geq 0,7 \mathrm{~m}^{2}$ vloeroppervlak per dier waarvan $\leq 0,4 \mathrm{~m}^{2}$ bestaande uit roosters, mestkelders onder de hokken en 80 130 dieren per afdeling. De bemeten conventionele huisvesting van zeugen bestond uit individuele huisvesting, gedeeltelijk roostervloer, mestkelders onder de vloer en 24-103 dieren per afdeling. De geanalyseerde dataset voor vleesvarkens was tot stand gekomen uit metingen gedurende twee opeenvolgende groeirondes per bedrijf.

Per groeironde werden metingen van de geuremissie uitgevoerd op vijf verschillende dagen, telkens tussen 10:00 en 12:00 uur. Tot slot werden de geurconcentraties per meetdag door twee verschillende bemonsteringen (in duplo) bepaald. Per bedrijfslocatie met vleesvarkens waren er derhalve 2 rondes $\times 5$ meetdagen $\times 2$ bemonsteringen $=20$ waarnemingen aanwezig in de dataset. De geanalyseerde dataset voor zeugen was tot stand gekomen uit metingen gedurende twee perioden van elk vier weken: één periode in de zomer en één periode in de winter. Per periode werden metingen van de geuremissie uitgevoerd op vijf verschillende dagen, telkens tussen 10:00 en 12:00 uur met eveneens duplo waarnemingen. Per bedrijfslocatie waren er derhalve eveneens 2 perioden $\times 5$ meetdagen $\times 2$ bemonsteringen $=20$ waarnemingen aanwezig.

De emissiegetallen werden getransformeerd naar natuurlijke logaritmen en vervolgens geanalyseerd met een mixed lineair model met bepaling van variantiecomponenten (niveaus: tussen-bedrijf, binnen-bedrijf, en tussen-bemonstering). De verkregen variantiecomponenten werden uitgedrukt als relatieve standaarddeviaties (=variatiecoëfficiënt). Aan de hand van de uitkomsten werd verkend op welke niveaus welke variatie te vinden was en wat dit betekende voor het inrichten van bemonsteringstrategieën. Het op dat moment geldende Groen Label meetprotocol (VROM, 1996) schreef voor dat er uitgebreid diende te worden gemeten aan één bedrijfslocatie.

Uit de studie bleek een forse tussenbedrijfsvariatie in geuremissie voor met name het huisvestingssysteem voor vleesvarkens: een relatieve standaarddeviatie tussen bedrijfslocaties van $22 \%$. Stellen we de gemiddelde geuremissie op $100 \%$, corresponderend met de geuremissiefactor van $23 \mathrm{OU}_{\mathrm{E}} / \mathrm{s}$ per dier ${ }^{2}$ op absolute schaal, nemen we de $22 \%$ als fixed waarde, en veronderstellen we de emissiecijfers normaal verdeeld, dan volgen uit formule (1) indicatieve 95\%betrouwbaarheidsintervallen van (EF $[95 \%-B I])$ :

- 23 [-22-68] OUE/s per dier bij $n=2$ bedrijfslocaties ( $\pm 45 \mathrm{OU}_{\mathrm{E}} / \mathrm{s}$ per dier)

- 23 [15-31] OUE/s per dier bij $n=4$ bedrijfslocaties ( \pm 8 OUE/s per dier)

- 23 [19-27] OUE/s per dier bij $n=8$ bedrijfslocaties ( \pm 4 OUE/s per dier)

De tussenbedrijfsvariatie in geuremissie voor het huisvestingssysteem voor zeugen bedroeg $2 \%$. Dezelfde berekeningen voor het huisvestingsysteem voor zeugen leiden tot indicatieve 95\%betrouwbaarheidsintervallen van (EF $[95 \%-B I])$ :

- $18,7[15,3-22,1]$ OUE/s per dier bij $n=2$ bedrijfslocaties ( $\pm 3,4 \mathrm{OU}_{\mathrm{E}} / \mathrm{s}$ per dier)

- $18,7[18,1-19,3]$ OU $\mathrm{E} / \mathrm{s}$ per dier bij $n=4$ bedrijfslocaties ( $\pm 0,6 \mathrm{OU}_{\mathrm{E}} / \mathrm{s}$ per dier)

- $18,7[18,4-19,0] \mathrm{OU}_{\mathrm{E}} / \mathrm{s}$ per dier bij $n=8$ bedrijfslocaties ( $\pm 0,3$ OUE/s per dier)

\footnotetext{
${ }^{2}$ Rav code D 3.100 Vleesvarkens overige huisvestingssystemen
} 
Opgemerkt moet worden dat bovenstaande uitkomsten een ruwe indruk geven van de onzekerheid waarmee de geuremissiefactor omgeven is bij verschillende aantallen bedrijfslocaties. In werkelijkheid zal de tussenbedrijfsvariatie met het beschikbaar komen van meer bedrijfslocaties steeds accurater worden ingeschat (de steekproefvariantie benadert de werkelijke variantie steeds dichter). Tevens zouden de betrouwbaarheidsintervallen idealiter bepaald moeten worden vanuit de analyse op de natuurlijke logaritmen van de emissiegetallen.

De studie van Ogink et al. (1997) concludeerde destijds dat er forse tussenbedrijfsvariatie in geuremissie kan bestaan en dat niet alleen duplo-variatie en binnenbedrijfsvariatie belangrijk zijn (zoals tot dat moment opgenomen in de één-bedrijfslocatie-strategie van het Groen Label protocol), maar dat bemonsteringstrategieën in protocollen gebaseerd moeten zijn op een analyse van alle bronnen van variatie, inclusief tussenbedrijfsvariatie; dit laatste in de vorm van het includeren van meerdere bedrijfslocaties in de bemonsteringsstrategie.

\subsubsection{Ammoniakemissiefactoren varkenscategorieën (Mosquera et al., 2008)}

Tijdens voornoemde meetcampagne naar geuremissiefactoren (Ogink \& Lens, 2001) zijn tevens ammoniakconcentraties en -emissies bepaald. Daarnaast waren data voorhanden van huisvestingssystemen waarvan de ammoniakemissie bemeten was volgens het Groen Label protocol uit 1996. De data uit beide onderzoekslijnen zijn in één dataset samengebracht voor de diercategorieën dragende zeugen, kraamzeugen, biggen en vleesvarkens, alsook voor de verschillende huisvestingssystemen binnen die diercategorieën, en geanalyseerd door Mosquera et al. (2008).

Uit de analyses bleek de overall tussenbedrijfsvariatie (uitgedrukt als relatieve standaarddeviatie tussen bedrijven; over huisvestingssystemen heen) omvangrijk te zijn: $31 \%$ voor dragende zeugen, $27 \%$ voor kraamzeugen, $66 \%$ voor biggen en $46 \%$ voor vleesvarkens (Mosquera et al., 2008 ; tabel 31 op p. 37).

Uitgaande van de conventionele huisvestingssystemen voor de genoemde diercategorieën (met Rav codes D X.100), van voornoemde relatieve standaarddeviaties, $n=4$ bemeten bedrijfslocaties en een normale verdeling van de ammoniakemissies, dan volgen uit de berekeningen in formule (1) indicatieve 95\%-betrouwbaarheidsintervallen van (EF [95\%-BI]):

- $4.2[2,1-6,3] \mathrm{kg} / \mathrm{jaar}$ per dierplaats voor dragende zeugen $( \pm 2,1 \mathrm{~kg} / \mathrm{jaar}$ per dierplaats)

- $8,3[4,7-11,9] \mathrm{kg} / \mathrm{jaar}$ per dierplaats voor kraamzeugen $( \pm 3,6 \mathrm{~kg} / \mathrm{jaar}$ per dierplaats)

- $0,69[0,0-1,4] \mathrm{kg} / \mathrm{jaar}$ per dierplaats voor biggen $( \pm 0,7 \mathrm{~kg} / \mathrm{jaar}$ per dierplaats)

- $3,0[0,8-5,2] \mathrm{kg} / \mathrm{jaar}$ per dierplaats voor vleesvarkens ( $\pm 2,2 \mathrm{~kg} / \mathrm{jaar}$ per dierplaats)

Mosquera et al. (2008) concluderen o.a. dat hun studie en die van Ogink et al. (1997) aanzienlijke variatie in ammoniak- en geuremissie tonen binnen één en hetzelfde huisvestingssysteem: zowel tussen bedrijven als in de tijd binnen een bedrijf. Verder concluderen Mosquera et al. (2008) dat de eindnauwkeurigheid van een emissiefactor met een factor 2 kan worden vergroot door het aantal bedrijfslocaties te vergroten van één naar vier en binnen een bedrijf minder vaak te meten.

\subsubsection{Ammoniakemissiefactor melkvee Rav A 1.100 (Ogink et al., 2014)}

In 2014 brachten Ogink et al. een advies uit voor het actualiseren van de ammoniakemissiefactoren in hoofdcategorie A (Rundvee) van de Rav op basis van alle beschikbare ammoniakemissiecijfers aan rundveestallen tot dat moment. Bijlage 2 bij deze studie bevat een statistische analyse van in totaal 98 24-uursmetingen uitgevoerd bij 8 bedrijfslocaties met een conventionele stal met roostervloer en 9 bedrijfslocaties met een stal met een (beoogd) ammoniakemissiearm huisvestingssysteem.

Vergelijkbaar met de studie van Ogink et al. (1997) zijn de natuurlijke logaritmen van de emissiecijfers geanalyseerd met een mixed lineair model met bepaling van o.a. de tussenbedrijfsvariantie. Op basis van de 17 bedrijfslocaties wordt de tussenbedrijfsvariatie geschat op circa $15 \%$, uitgedrukt als relatieve standaarddeviatie tussen bedrijven. Dit is aanzienlijk lager dan gevonden bij de varkenscategorieën door Mosquera et al. (2008). 
Uitgaande van het conventionele huisvestingssysteem voor melkkoeien (een ligboxenstal met roostervloer en mestkelders; Rav code A 1.100) met een emissiefactor van $13 \mathrm{~kg} / \mathrm{jaar}$ per dierplaats, voornoemde relatieve standaarddeviatie, $n=4$ bemeten bedrijfslocaties en een normale verdeling van de ammoniakemissies, dan volgt uit de berekening in formule (1) een indicatief $95 \%$ betrouwbaarheidsinterval van (EF [95\%-BI]): 13 [11-15] kg/jaar per dierplaats ( $\pm 2 \mathrm{~kg} / \mathrm{jaar}$ per dierplaats oftewel $\pm 15 \%$ ). Dit $95 \%$-BI geeft een indruk van de onzekerheid waarmee de ammoniakemissiefactor voor de conventionele ligboxenstal is omgeven: 13 is de meest waarschijnlijke waarde, maar bij 95\% betrouwbaarheid kan deze waarde liggen tussen 11 en 15.

\subsubsection{Fijnstofemissiefactoren (Winkel et al., 2015)}

In 2015 publiceerden Winkel et al. de resultaten van een omvangrijke meetcampagne naar de emissie van fijnstof ( $\mathrm{PM}_{100}, \mathrm{PM}_{10}$ en $\mathrm{PM}_{2,5}$ ) bestaande uit ruim tweehonderd 24-uursmetingen uitgevoerd bij 13 verschillende huisvestingssystemen voor pluimvee, varkens en rundvee tussen circa 2007 en 2010. In deze studie is als eerste indruk tevens de tussenbedrijfsvariatie en binnenbedrijfsvariatie bepaald over alle diercategorieën en huisvestingssystemen heen. Uitgedrukt als relatieve standaarddeviatie bedroegen deze respectievelijk $23 \%$ en $68 \%$ voor de $\mathrm{PM}_{10}$ emissie en $26 \%$ en $93 \%$ voor de $\mathrm{PM}_{2,5}$ emissie. Deze waarden liggen redelijk in lijn met die gevonden voor geur- en ammoniakemissies door Ogink et al. (1997), Mosquera et al. (2008) en Ogink et al. (2014). Een diepgaander analyse van een grotere dataset is nodig om deze waarden en hun betekenis voor meetprotocollen in te schatten.

\subsection{Betekenis variatiebronnen voor meetprotocollen}

De studies van Ogink et al. (1997) en Mosquera et al. (2008) hebben laten zien dat een bemeten emissie op één bedrijfslocatie (zoals gangbaar in het Groen Label protocol uit 1996) onvoldoende voorspellende waarde heeft voor de emissie van een tweede, derde, vierde, enzovoort, bedrijfslocatie, en onvoldoende representatief is om te dienen als maat voor de werkelijke gemiddelde emissie van een huisvestingssysteem zoals die vastgesteld zou kunnen worden door alle in Nederland bestaande bedrijfslocaties met het huisvestingssysteem te onderwerpen (zie par. 2.1). Sinds 2013 wordt daarom in het Nederlandse meetprotocol voor ammoniak gewerkt met een zogenaamde 'multi-site-approach' of 'multi-farm-approach' (zie: Ogink et al., 2013). In de internationale meetprotocollen van VERA t.a.v. emissies van huisvestingssystemen (VERA, 2018a) en emissiereducties van emissie reducerende technieken (VERA, 2018b) is deze aanpak ook opgenomen. In deze protocollen moeten respectievelijk vier en twee bedrijfslocaties (met een case-control opzet) worden bemeten ${ }^{3}$.

In voornoemde protocollen is voorgeschreven dat emissie reducerende technieken op twee bedrijfslocaties worden bemeten om op het kleinst mogelijke niveau van één herhaling te verifiëren of de prestatie van een techniek op de eerste bedrijfslocatie reproduceerbaar is op een tweede bedrijfslocatie. Analyses t.a.v. variatiebronnen/onzekerheden bij fijnstof reducerende technieken zijn echter nog nooit gedaan. Toch is het zeer aannemelijk dat deze variatie bestaat. Mogelijk is die variatie kleiner voor technieken die qua werkingsprincipe zeer stabiel/robuust zijn (zoals technieken op basis van filters ontworpen voor een zekere afvang van deeltjes tot een zekere deeltjesdiameter) en groter voor technieken die een gevoeliger werkingsprincipe hebben of waarbij de prestatie van de techniek interacteert met het stalgebouw (zoals ionisatietechnieken waarbij het stalgebouw als collectoroppervlak dient) of met managementfactoren. Geprobeerd wordt de bedrijfszekerheid (en daarmee reproduceerbaarheid = betrouwbaarheid) van reductietechnieken te borgen door vast te leggen dat technieken dienen te voldoen aan de technische eisen conform bijbehorende BWLbeschrijvingen of leaflets. In hoofdstuk 4 van dit rapport worden de onzekerheidsberekeningen uitgevoerd voor fijnstof reducerende technieken.

\footnotetext{
${ }^{3}$ Overigens mag een emissiefactor van een huisvestingssysteem ook worden vastgesteld door een case-control opzet op twee bedrijfslocaties als alternatief voor het vaststellen van een emissiewaarde uit vier bedrijfslocaties.
} 


\section{Keuze en berekeningswijze onzekerheidsmarge}

\subsection{Keuze voor een type onzekerheidsmarge}

Het eerste doel van deze deskstudie was om een onzekerheidsmarge te bepalen als compensatie voor de extra onzekerheid in het reductiepercentage die ontstaat wanneer een techniek wordt bemeten bij één i.p.v. twee bedrijfslocaties, zoals dat gedaan is in de fijnstofpilots in de Gelderse Vallei. Uit paragraaf 2.3 volgt dat het onmogelijk is een $95 \%$-BI rondom één bedrijfsgemiddeld reductiepercentage uit een pilot te berekenen. Er is immers überhaupt geen tussenbedrijfsspreiding benodigd voor het berekenen van de SD en SE in formule 1. Er kan slechts een 95\%-BI voor het gemiddelde reductiepercentage van de bemeten bedrijfslocatie worden bepaald op basis van de zes herhaalde 24-uursmetingen op dat bedrijf.

Tijdens een overleg tussen vertegenwoordigers van het Ministerie van IenW, RVO, de TAP en WLR in februari 2020 is besproken welke mogelijkheden er bestaan voor een onzekerheidsmarge voor de fijnstofpilots. De volgende mogelijkheden met elk hun mitsen en maren passeerden de revue:

- de ondergrens van een 95\%-BI voor het gemiddelde reductiepercentage van de bemeten bedrijfslocatie op basis van de zes herhaalde 24-uursmetingen op dat bedrijf. Door de substantiële binnenbedrijfsvariatie (spreiding tussen de zes reductiepercentages) zou deze optie leiden tot een ondergrens die fors lager is dan het gemiddelde (maar wel boven nul procent, d.w.z. statistisch significant). Deze optie is daarmee erg "streng", zeker gezien de grote onzekerheid die geaccepteerd wordt bij emissiefactoren (zie de bespreking in hoofdstuk 2) en fijnstof reducerende technieken in de Lijst bemeten bij twee bedrijfslocaties (zie hoofdstuk 4; enkele van de berekeningen waren op dat moment reeds voorhanden);

- een onzekerheidsmarge op basis van een inventarisatie van in de literatuur gerapporteerde reductiepercentages van vergelijkbare technieken als in de pilots. Deze optie heeft als bezwaar dat voor tenminste de helft van de technieken geen meetgegevens voorhanden zijn in de literatuur;

- aftrek van 0,15* het gemiddelde bemeten reductiepercentage: bij voorlopige emissiefactoren voor ammoniak wordt als marge genomen de modelmatig (met het Snelstal-model) ingeschatte ammoniakemissie minus 15\% van de maximale emissiewaarde uit het Besluit emissiearme huisvesting (Beh) voor het conventionele huisvestingssysteem van de betreffende diercategorie. Deze aftrek van $15 \%$ heeft echter als bezwaar dat deze tot stand is gekomen op basis van expert judgement; dit betreft dus een minimaal onderbouwde waarde;

- aftrek van een onzekerheidsmarge op basis van de datasets van reeds in de Lijst opgenomen fijnstof reducerende technieken op basis van metingen aan twee bedrijfslocaties. Deze onzekerheid in andere technieken uit historische meetcampagnes wordt dan als schatting genomen voor de extra onzekerheid die ontstaat wanneer een techniek (voorlopig) wordt bemeten bij één i.p.v. twee bedrijfslocaties.

Bij de vertegenwoordigers van IenW, RVO en TAP bestond consensus over de laatste bullet als zijnde de beste beschikbare optie voor het uitwerken van een onzekerheidsmarge. Op grond hiervan is de onzekerheidsmarge als volgt uitgewerkt. 


\subsection{Berekeningswijze gekozen type onzekerheidsmarge}

De grondgedachte achter de veiligheidsmarge is dat reductiepercentages van fijnstof reducerende technieken (tot aan het starten van de fijnstofpilots) werden bepaald op basis van twee bedrijfslocaties met elk hun bedrijfsgemiddelde reductie. En verder dat het reductiepercentage dat werd opgenomen in de Lijst het gemiddelde (=mediaan in een normale verdeling) van de twee bedrijfsgemiddelden was. Dit is grafisch weergegeven in Figuur 1.

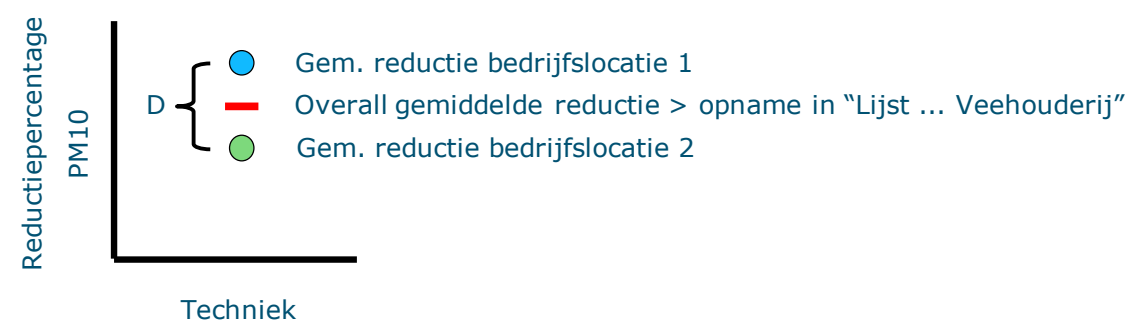

Figuur 1 Het reductiepercentage van een techniek als gemiddelde van de twee bedrijfsgemiddelden.

Een onzekerheidsmarge kan nu berekend worden door voor elke in de Lijst opgenomen techniek het tussenbedrijfsverschil $D$ te bepalen. Hiertoe zijn van alle technieken de datasets opgezocht in de projectdossiers van de betreffende meetcampagnes. Tijdens het overleg tussen vertegenwoordigers van het Ministerie van IenW, RVO, de TAP en WLR in februari 2020 is besloten de onzekerheidsmarge vervolgens eenvoudig te berekenen als: $0,5 *$ de mediaan over alle tussenbedrijfsverschillen $D_{i}$. 


\section{$4 \quad$ Resultaten en discussie}

\subsection{Onzekerheid bij technieken bemeten bij meerdere bedrijfslocaties}

De berekeningen van onzekerheden (95\%-BI) en tussenbedrijfsverschillen zijn weergegeven in tabellen $1 \mathrm{t} / \mathrm{m} 11$ op de volgende pagina's.

De tabellen zijn gelijk van opbouw. Elke tabel bevat de gegevens en uitkomsten van één fijnstof reducerende techniek zoals die opgenomen is in de Lijst Emissiefactoren fijnstof voor veehouderij. De volgende zaken worden weergegeven:

- 'Reducties metingen': de doorgaans 12 (soms iets minder) reductiepercentages zoals die bepaald zijn aan de hand van 24-uursmetingen in een case-control strategie op twee bedrijfslocaties, gespreid over het jaar en de productieperiode van de dieren. Onder elk reductiepercentage liggen feitelijk twee meetpunten (totaal 24 waarnemingen):

- een emissie in een case-stal met de techniek versus de emissie in een identieke controlestal zonder techniek (een zogenaamde 'fysieke case-control');

- een emissie in een stal met de techniek op een dag waarbij de techniek ingeschakeld was versus de emissie op een dag waarbij de techniek uitgeschakeld was (een zogenaamde 'case-control in de tijd')

- een emissie in een stal met een end-of-pipe techniek zoals bemeten ná de techniek versus vóór de techniek.

- 'Gem. Red.': het rekenkundig gemiddelde over de individuele reductiepercentages.

- 'Gem. E > Red.': de gemiddelde reductie door eerst per case en controle de gemiddelde emissies te berekenen en over die twee eindcijfers de reductie.

- 'Gem. $E_{(1,2,3)}>$ Red.': de gemiddelde reductie door zowel bij de case als de controle de individuele metingen in te delen in drie productiestadia (bij vleeskuikens). Vervolgens worden per behandeling (case, controle) en per productiestadium $(1,2,3)$ de gemiddelde emissies berekend. De drie stadiagemiddelden worden vervolgens gemiddeld tot een overall gemiddelde emissie voor de case en een overall gemiddelde emissie voor de controle. Vervolgens wordt het reductiepercentage berekend over de twee eindcijfers. Deze methode is nodig bij vleeskuikens waar zowel het ventilatiedebiet, de fijnstofconcentratie en de fijnstofemissie exponentieel toenemen met de leeftijd van de dieren. Reductiepercentages gemeten in het eerste productiestadium bij een zeer lage emissie hebben bij het simpelweg nemen van een rekenkundig gemiddelde over de individuele reductiepercentages een onevenredig groot aandeel in het eindreductiepercentage. Daarnaast heeft het exponentiele karakter van ventilatiedebiet, fijnstofconcentratie en fijnstofemissie soms ook invloed op de prestatie van de techniek wat meegenomen moet worden in de meetstrategie en berekeningswijze.

- 'Var.': de variantie over de doorgaans 12 individuele reductiepercentages danwel de 2 bedrijfsgemiddelde reductiepercentages. Het eerste type is een variantie waarin voorbij wordt gegaan aan tussenbedrijfsvariatie en heeft dus de neiging de werkelijke spreiding te onderschatten.

- 'SD abs.': de standaarddeviatie; de wortel uit de variantie

- 'SD rel.': voornoemde 'SD abs.' uitgedrukt als percentage van het gemiddelde (=variatiecoëfficiënt).

- 'SE van gem.': de standard error van de gemiddelde reductie (=standaardfout).

- '95\%-BI van gem.': het 95\%-betrouwbaarheidsinterval voor voornoemde gemiddelde.

- 'Geaccept. onzekerh.': de onzekerheid die op dit moment geaccepteerd wordt voor de techniek uitgedrukt in $\pm \ldots$ absolute reductieprocenten (de breedte van het 95\%-BI rondom het gemiddelde).

In tabel 12 is een overzicht weergegeven van de geaccepteerde onzekerheden bij de 11 fijnstof reducerende technieken, gebaseerd op standaardfout tussen de bedrijfsgemiddelden. Uit tabellen 1 
t/m 11 en tabel 12 blijkt dat de geaccepteerde onzekerheid groot kan zijn. Uitgedrukt als 95\%betrouwbaarheidsinterval in absolute reductieprocenten varieert deze tussen het gemiddelde \pm 8 reductieprocenten en het gemiddelde \pm 202 reductieprocenten (mediaan: \pm 119 reductieprocenten; rekenkundig gemiddelde: \pm 88 reductieprocenten). De brede betrouwbaarheidsintervallen worden o.a. veroorzaakt door het feit dat alle technieken (behalve de strooiselmestschuif) bij $n=2$ bedrijfslocaties zijn bemeten. De zeer beperkte informatie over tussenbedrijfsvariatie leidt per definitie tot een grote onnauwkeurigheid in de inschatting van deze spreiding. Hierdoor moet gerekend worden met een Student's t-waarde van 12,706. De standaardfout over de twee bedrijfsgemiddelde reductiepercentages moet dan zeer beperkt zijn, anders worden brede intervallen verkregen.

\subsection{Tussenbedrijfsverschillen en onzekerheidsmarge}

In tabel 13 is een overzicht gegeven van de tussenbedrijfsverschillen (zie figuur 1 ) van de 11 fijnstof reducerende technieken. De tussenbedrijfsverschillen variëren tussen 2,2 en 31,8 absolute reductieprocenten. Het mediane tussenbedrijfsverschil bedraagt 19,4. De onzekerheidsmarge voor de fijnstofpilots $\left(0,5 *\right.$ mediaan over $\left.D_{i}\right)$ bedraagt afgerond op hele cijfers: 10 absolute procentpunten.

In tabel 14 zijn de tussenbedrijfsverschillen weergegeven per plaats van de techniek in het stalsysteem en per werkingsmechanisme van de techniek, beide als potentiele categorie voor verbijzondering van een hierboven berekende overall onzekerheidsmarge. De gegevens in deze tabel geven geen aanleiding een verbijzondering aan te brengen.

In figuur 2 is de relatie weergegeven tussen het tussenbedrijfsverschil van een techniek en het gemiddelde reductiepercentage. Uit deze figuur en de statistische toetsing van de regressiecoëfficiënt blijkt dat het tussenbedrijfsverschil niet afhangt van het niveau van de reductie $(P=0,682)$.

Tabel 1 Gemeten reductiepercentages, gemiddelde reductiepercentages per bedrijfslocatie, het verschil tussen de bedrijfsgemiddelde reductiepercentages, het overall gemiddelde reductiepercentage en de onzekerheid rondom het overall gemiddelde reductiepercentage, uitgedrukt als 95\% betrouwbaarheidsinterval voor de techniek: E 7.1 oliefilmsysteem met drukleidingen 54\% fijnstofemissiereductie (BWL 2009.17).

\begin{tabular}{|c|c|c|c|c|c|c|c|c|c|c|c|c|c|c|c|}
\hline & \multicolumn{6}{|c|}{ Reducties metingen } & \multirow{2}{*}{\begin{tabular}{|c|}
$\begin{array}{c}\text { Gem. } \\
\text { Red. }\end{array}$ \\
70.6
\end{tabular}} & \multirow{2}{*}{\begin{tabular}{|r|}
$\begin{array}{c}\text { Gem. } \\
\text { E Red. }\end{array}$ \\
46.3
\end{tabular}} & \multirow{2}{*}{$\begin{array}{r}\begin{array}{c}\text { Gem. } E_{(1,2)} \\
>\text { Red. }\end{array} \\
\mathbf{6 5 . 1}\end{array}$} & \multirow{2}{*}{$\begin{array}{l}\text { Var. } \\
273.9\end{array}$} & \multirow{2}{*}{$\begin{array}{l}\begin{array}{l}\text { SD } \\
\text { abs. } \\
16.5\end{array}\end{array}$} & \multirow{2}{*}{$\begin{array}{l}\text { SD } \\
\text { rel. } \\
25.4\end{array}$} & \multirow{2}{*}{$\begin{array}{l}\begin{array}{c}\text { SE } \\
\text { gem. }\end{array} \\
6.8\end{array}$} & \multirow{2}{*}{\begin{tabular}{c|}
$\begin{array}{c}95 \%-\mathrm{BI} \\
\mathrm{gem} .\end{array}$ \\
$48-82$
\end{tabular}} & \multirow{2}{*}{$\begin{array}{r}\text { Geaccept. } \\
\text { onzekerh. } \\
\pm 17\end{array}$} \\
\hline Bedrijf 1 & 79 & 87 & 83 & 53 & 47 & 73 & & & & & & & & & \\
\hline Bedrijf 2 & 58 & 63 & 46 & 48 & 35 & $*$ & 50.0 & 48.6 & 46.3 & 115.6 & 10.8 & 23.2 & 4.8 & $33-60$ & \pm 13 \\
\hline Bedrijf $1 \mid 2(n=2)$ & & & & & & & 61.2 & 47.3 & 55.0 & 210.6 & 13.3 & 24.2 & 9.4 & $-64-174$ & \pm 119 \\
\hline Verschil B2 vs. B1 & & & & & & & & & 18.8 & & & & & & \\
\hline
\end{tabular}

- Data afkomstig uit Winkel et al. (2011), WLR Rapport 392: https://edepot.wur.nl/166950.

- N.B. Er is olie verneveld vanaf dag 21 in ronde. De reductie van $55 \%$ betreft de reguliere emissie tot dag 21 plus de gereduceerde emissie daarna. De emissie van dag 1-21 is ingeschat door de emissie te nemen van dag 22-42 vermenigvuldigd met 0.1. M.a.w. de emissie in de eerste helft van de groeironde bedraagt $10 \%$ van die in de tweede helft van de groeironde. Dit verhoudingsgetal is gebaseerd op de data in WLR Rapport 275.

- Het verschil B2 vs. B1 van 18.8 op het gemiddelde van 55.0 procentpunten reductie bedraagt relatief $34.2 \%$.

Tabel 2 Gemeten reductiepercentages, gemiddelde reductiepercentages per bedrijfslocatie, het verschil tussen de bedrijfsgemiddelde reductiepercentages, het overall gemiddelde reductiepercentage en de onzekerheid rondom het overall gemiddelde reductiepercentage, uitgedrukt als 95\%

betrouwbaarheidsinterval voor de techniek: E 7.2 ionisatiesysteem met negatieve coronadraden 49\% fijnstofemissiereductie (BWL 2009.18. V1).

\begin{tabular}{|c|c|c|c|c|c|c|c|c|c|c|c|c|c|c|c|}
\hline & Redur & ties & letir & & & & \begin{tabular}{l|} 
Gem. \\
Red.
\end{tabular} & $\begin{array}{c}\text { Gem. } \\
\text { E > Red. }\end{array}$ & 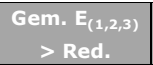 & Var. & $\begin{array}{l}\text { SD } \\
\text { abs. }\end{array}$ & $\begin{array}{l}\text { SD } \\
\text { rel. }\end{array}$ & $\begin{array}{c}\text { SE } \\
\text { gem. }\end{array}$ & $\begin{array}{c}95 \%-\mathrm{BI} \\
\text { gem. }\end{array}$ & \begin{tabular}{|l|} 
Geaccept. \\
onzekerh.
\end{tabular} \\
\hline Bedrijf 1 & 34 & 62 & -4 & 5 & 55 & 60 & 35.4 & 46.3 & 50.0 & 826.6 & 28.8 & 57.5 & 11.7 & $20-80$ & \pm 30 \\
\hline Bedrijf 2 & 64 & 50 & 69 & 67 & 27 & 69 & 57.7 & 48.6 & 47.2 & 271.1 & 16.5 & 34.9 & 6.7 & $30-65$ & \pm 17 \\
\hline Bedrijf $1 \mid 2(n=2)$ & & & & & & & 46.6 & 47.3 & 49.1 & 248.7 & 1.7 & 3.4 & 1.2 & $34-64$ & \pm 15 \\
\hline Verschil B2 vs. B1 & & & & & & & & & 2.8 & & & & & & \\
\hline
\end{tabular}

- Data afkomstig uit Winkel et al. (2011), WLR Rapport 462: https://edepot.wur.nl/166947.

- De onzekerheid van 15 procentpunten op het gemiddelde van 49 procentpunten reductie bedraagt relatief $30.4 \%$.

- Het verschil B2 vs. B1 van 2.8 op het gemiddelde van 49.1 procentpunten reductie bedraagt relatief $5.7 \%$. 
Tabel 3 Gemeten reductiepercentages, gemiddelde reductiepercentages per bedrijfslocatie, het verschil tussen de bedrijfsgemiddelde reductiepercentages, het overall gemiddelde reductiepercentage en de onzekerheid rondom het overall gemiddelde reductiepercentage, uitgedrukt als 95\% betrouwbaarheidsinterval voor de techniek: E 7.3 waterluchtwassysteem 33\%

fijnstofemissiereductie (BWL 2009.19.V2).

\begin{tabular}{|c|c|c|c|c|c|c|c|c|c|c|c|c|c|c|c|}
\hline & Redur & ties & letir & & & & $\begin{array}{l}\text { Gem. } \\
\text { Red. }\end{array}$ & $\begin{array}{c}\text { Gem. } \\
\text { E > Red. }\end{array}$ & $\begin{array}{c}\text { Gem. } E_{(1,2,3)} \\
>\text { Red. }\end{array}$ & Var. & $\begin{array}{l}\text { SD } \\
\text { abs. }\end{array}$ & $\begin{array}{l}\text { SD } \\
\text { rel. }\end{array}$ & $\begin{array}{c}\text { SE } \\
\text { gem. }\end{array}$ & $\begin{array}{c}95 \%-\mathrm{BI} \\
\text { gem. }\end{array}$ & \begin{tabular}{|l|} 
Geaccept. \\
onzekerh.
\end{tabular} \\
\hline Bedrijf 2 & 31 & 28 & 19 & 38 & 36 & 35 & 31.3 & - & - & 47.3 & 6.9 & 22.0 & 2.8 & $24-39$ & \pm 7 \\
\hline Bedrijf $1 \mid 2(n=2)$ & & & & & & & 47.2 & - & - & 505.1 & 22.5 & 47.6 & 15.9 & $-155-249$ & \pm 202 \\
\hline Verschil B2 vs. B1 & & & & & & & 31.8 & & & & & & & & \\
\hline
\end{tabular}

- Data afkomstig uit Melse et al. (2011), WLR Rapport 502: https://edepot.wur.nl/184259.

- N.B. Hier verschillen de gemiddelde reductiepercentages van de twee bedrijven meer dan gebruikelijk. De auteurs noemen hiervoor twee verklaringen: bij bedrijf 1 is een (stofafvangende) droogtunnel aanwezig voorgeschakeld aan de waterwasser en de verblijfstijd van de lucht in de waterwasser is groter voor bedrijf 1 . Bij vaststelling van het reductiepercentage voor de "Lijst Emissiefactoren ... voor veehouderij" is daarom uitgegaan van alleen het resultaat bij bedrijf 2 (worst-case benadering).

- De onzekerheid van 8 procentpunten op het gemiddelde van 40.1 procentpunten reductie bedraagt relatief $19.7 \%$

- Het verschil B2 vs. B1 van 1.2 op het gemiddelde van 40.1 procentpunten reductie bedraagt relatief $3.1 \%$.

Tabel 4 Gemeten reductiepercentages, gemiddelde reductiepercentages per bedrijfslocatie, het verschil tussen de bedrijfsgemiddelde reductiepercentages, het overall gemiddelde reductiepercentage en de onzekerheid rondom het overall gemiddelde reductiepercentage, uitgedrukt als $95 \%$ betrouwbaarheidsinterval voor de techniek: $\mathbf{E} 7.4$ droogfilterwand $40 \%$ fijnstofemissiereductie (BWL 2010.29.V2).

\begin{tabular}{|c|c|c|c|c|c|c|c|c|c|c|c|c|c|c|c|}
\hline & \multicolumn{6}{|c|}{ Reducties metingen } & \multirow{2}{*}{\begin{tabular}{|c|}
$\begin{array}{c}\text { Gem. } \\
\text { Red. }\end{array}$ \\
$\mathbf{4 0 . 7}$ \\
$\mathbf{3 9 . 4}$
\end{tabular}} & $\begin{array}{c}\text { Gem. } \\
\text { E > Red. }\end{array}$ & $\begin{array}{c}\text { Gem. } E_{(1,2,3)} \\
>\text { Red. }\end{array}$ & Var. & $\begin{array}{l}\text { SD } \\
\text { abs. }\end{array}$ & $\begin{array}{l}\text { SD } \\
\text { rel. }\end{array}$ & $\begin{array}{c}\text { SE } \\
\text { gem. }\end{array}$ & $\begin{array}{l}95 \%-B I \\
\text { gem. }\end{array}$ & \begin{tabular}{|r|}
$\begin{array}{l}\text { Geaccept. } \\
\text { onzekerh. }\end{array}$ \\
\pm 12
\end{tabular} \\
\hline Bedrijf 2 , eigen variantie & 29 & $*$ & 29 & 45 & 42 & 53 & & & & 114.6 & 10.7 & 27.2 & 4.8 & $26-53$ & \pm 13 \\
\hline Bedrijf $1 \mid 2(n=2)$ & & & & & & & 40.1 & & & 0.8 & 0.9 & 2.2 & 0.6 & $32-48$ & \pm 8 \\
\hline Verschil B2 vs. B1 & & & & & & & 1.2 & & & & & & & & \\
\hline
\end{tabular}

- Data afkomstig uit Winkel et al. (2011), WLR Rapport 394: https://edepot.wur.nl/170798.

- De onzekerheid van 8 procentpunten op het gemiddelde van 40.1 procentpunten reductie bedraagt relatief $19.7 \%$.

- Het verschil B2 vs. B1 van 1.2 op het gemiddelde van 40.1 procentpunten reductie bedraagt relatief $3.1 \%$.

Tabel 5 Gemeten reductiepercentages, gemiddelde reductiepercentages per bedrijfslocatie, het verschil tussen de bedrijfsgemiddelde reductiepercentages, het overall gemiddelde reductiepercentage en de onzekerheid rondom het overall gemiddelde reductiepercentage, uitgedrukt als 95\% betrouwbaarheidsinterval voor de techniek: E 7.5 ionisatiefilter $\mathbf{5 7 \%}$ fijnstofemissiereductie (BWL 2011.01).

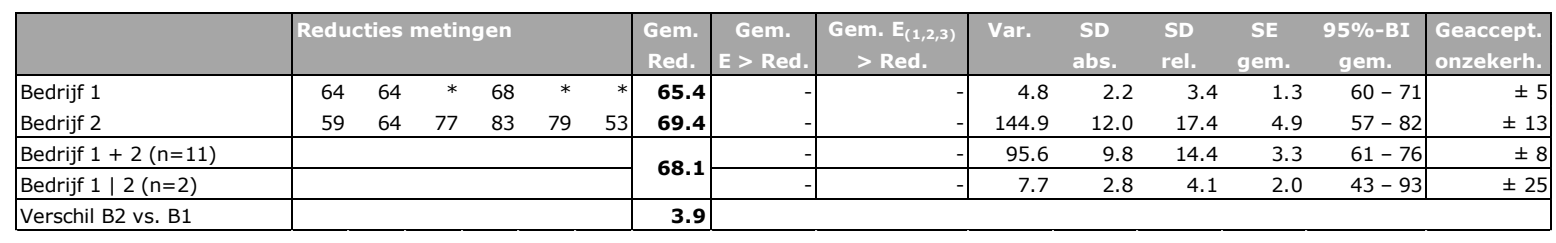

- Data afkomstig uit Winkel et al. (2012), WLR Rapport 440: http://edepot.wur.nl/200711.

- N.B. Deze dataset betreft alleen wintermetingen. Voor bedrijf 1 is nog een dataset in de zomer beschikbaar; deze is echter niet beschikbaar voor bedrijf 2 en daarom niet meegenomen in bovenstaande analyse. Dit resulteert in een zuivere vergelijking van bedrijfsgemiddelden, alhoewel het bedrijfsgemiddelde van bedrijf 1 maar op 3 i.p.v. 6 waarnemingen is gebaseerd.

- De onzekerheid van 25 procentpunten op het gemiddelde van 68.1 procentpunten reductie bedraagt relatief $36.7 \%$.

- Het verschil B2 vs. B1 van 3.9 op het gemiddelde van 68.1 procentpunten reductie bedraagt relatief $5.8 \%$. 
Tabel 6 Gemeten reductiepercentages, gemiddelde reductiepercentages per bedrijfslocatie, het verschil tussen de bedrijfsgemiddelde reductiepercentages, het overall gemiddelde reductiepercentage en de onzekerheid rondom het overall gemiddelde reductiepercentage, uitgedrukt als 95\% betrouwbaarheidsinterval voor de techniek: E 7.6 warmtewisselaar $31 \%$ fijnstofemissiereductie (BWL 2011.02.V6).

\begin{tabular}{|c|c|c|c|c|c|c|c|c|c|c|c|c|c|c|c|}
\hline & \multicolumn{6}{|c|}{ Reducties metingen } & \multirow{3}{*}{$\begin{array}{c}\begin{array}{c}\text { Gem. } \\
\text { Red. }\end{array} \\
\mathbf{8 8 . 7} \\
\mathbf{6 8 . 1} \\
\end{array}$} & \multirow{2}{*}{\begin{tabular}{|c}
$\begin{array}{c}\text { Gem. } \\
\text { E }>\text { Red. }\end{array}$ \\
-
\end{tabular}} & $\begin{array}{c}\text { Gem. } E_{(1,2,3)} \\
>\text { Red. }\end{array}$ & \multirow{2}{*}{$\begin{array}{l}\text { Var. } \\
55.6\end{array}$} & \multirow{2}{*}{$\begin{array}{l}\text { SD } \\
\text { abs. } \\
7.5\end{array}$} & \multirow{2}{*}{$\begin{array}{l}\begin{array}{l}\text { SD } \\
\text { rel. }\end{array} \\
8.4\end{array}$} & \multirow{2}{*}{\begin{tabular}{r}
\multicolumn{1}{c}{$\begin{array}{c}\text { SE } \\
\text { gem. }\end{array}$} \\
3.0
\end{tabular}} & \multirow{2}{*}{$\begin{array}{c}\begin{array}{c}95 \%-B I \\
\text { gem. }\end{array} \\
81-96\end{array}$} & \multirow{2}{*}{$\begin{array}{r}\text { Geaccept. } \\
\text { onzekerh. } \\
\pm 8\end{array}$} \\
\hline Bedrijf 1 & 93 & 92 & 91 & 74 & 91 & 92 & & & - & & & & & & \\
\hline Bedrijf 2 & 85 & 87 & 63 & 61 & 78 & 35 & & - & - & 385.6 & 19.6 & 28.8 & 8.0 & $48-89$ & \pm 21 \\
\hline Bedrijf $1 \mid 2(n=2)$ & & & & & & & 78.4 & - & - & 210.8 & 14.5 & 18.5 & 10.3 & $-52-209$ & \pm 130 \\
\hline Verschil B2 vs. B1 & & & & & & & 20.5 & & & & & & & & \\
\hline
\end{tabular}

Data afkomstig uit Ellen et al. (2012), WLR Rapport 621: https://edepot.wur.nl/259023.

De onzekerheid van 130 procentpunten op het gemiddelde van 78.4 procentpunten reductie bedraagt relatief $166.3 \%$. Het verschil B2 vs. B1 van 20.5 op het gemiddelde van 78.4 procentpunten reductie bedraagt relatief $26.2 \%$.

Tabel 7 Gemeten reductiepercentages, gemiddelde reductiepercentages per bedrijfslocatie, het verschil tussen de bedrijfsgemiddelde reductiepercentages, het overall gemiddelde reductiepercentage en de onzekerheid rondom het overall gemiddelde reductiepercentage, uitgedrukt als 95\% betrouwbaarheidsinterval voor de techniek: E 7.10 strooiselschuif bij volièrehuisvesting; 20\% emissiereductie ammoniak en fijnstof (BWL 2017.02).

\begin{tabular}{|c|c|c|c|c|c|c|c|c|c|c|c|c|}
\hline & Redu & ties & etingen & $\begin{array}{l}\text { Gem. } \\
\text { Red. }\end{array}$ & $\begin{array}{c}\text { Gem. } \\
\text { E > Red. }\end{array}$ & $\begin{array}{c}\text { Gem. } E_{(1,2,3)} \\
>\text { Red. }\end{array}$ & Var. & $\begin{array}{c}\text { SD } \\
\text { abs. }\end{array}$ & $\begin{array}{l}\text { SD } \\
\text { rel. }\end{array}$ & $\begin{array}{c}\text { SE } \\
\text { gem. }\end{array}$ & $\begin{array}{c}95 \%-\mathrm{BI} \\
\text { gem. }\end{array}$ & $\begin{array}{l}\text { Geaccept. } \\
\text { onzekerh. }\end{array}$ \\
\hline Bedrijf 2 & -5 & 26 & 17 & - & 12.2 & - & 253.4 & 15.9 & 130.4 & 9.2 & $-2-68$ & \pm 40 \\
\hline Bedrijf 4 & 25 & 39 & 5 & - & 22.8 & - & 284.1 & 16.9 & 73.8 & 9.7 & $-98-145$ & \pm 42 \\
\hline Bedrijf 5 & 28 & -2 & 40 & . & 21.9 & - & 477.4 & 21.8 & 99.7 & 12.6 & $-19-65$ & \pm 54 \\
\hline Bedrijf $1+\ldots+5(n=13)$ & & & & - & 21.8 & - & 357.5 & 18.9 & 86.8 & 5.2 & $10-33$ & \pm 12 \\
\hline
\end{tabular}

Data afkomstig uit Mosquera et al. (2016), WLR Rapport 995: https://library.wur.nl/WebQuery/wurpubs/fulltext/401249.

De onzekerheid van 9 procentpunten op het gemiddelde van 21.8 procentpunten reductie bedraagt relatief $41.5 \%$.

Het gemiddelde verschil van 8.5 op het gemiddelde van 21.8 procentpunten reductie bedraagt relatief $39.1 \%$.

Tabel 8 Gemeten reductiepercentages, gemiddelde reductiepercentages per bedrijfslocatie, het verschil tussen de bedrijfsgemiddelde reductiepercentages, het overall gemiddelde reductiepercentage en de onzekerheid rondom het overall gemiddelde reductiepercentage, uitgedrukt als 95\%

betrouwbaarheidsinterval voor de techniek: E 6.4.1 droogtunnel met geperforeerde banden $30 \%$ emissiereductie fijnstof (BWL 2005.06.V2).

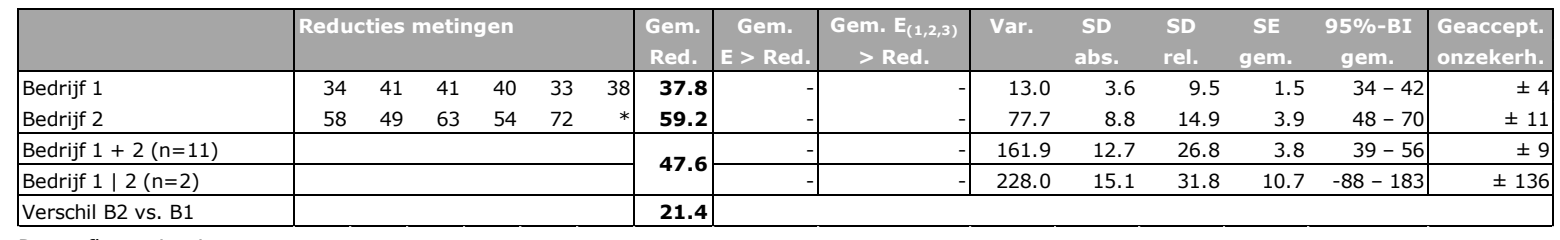

Data afkomstig uit:

- Winkel et al. (2011), WLR Rapport 280: https://edepot.wur.nl/166949;

- Winkel et al. (2014), WLR Rapport 731: https://edepot.wur.nl/166949.

De onzekerheid van 136 procentpunten op het gemiddelde van 47.6 procentpunten reductie bedraagt relatief $285.2 \%$. Het verschil B2 vs. B1 van 21.4 op het gemiddelde van 47.6 procentpunten reductie bedraagt relatief $44.9 \%$. 
Tabel 9 Gemeten reductiepercentages, gemiddelde reductiepercentages per bedrijfslocatie, het verschil tussen de bedrijfsgemiddelde reductiepercentages, het overall gemiddelde reductiepercentage en de onzekerheid rondom het overall gemiddelde reductiepercentage, uitgedrukt als 95\% betrouwbaarheidsinterval voor de techniek: E 6.4.2 droogtunnel met geperforeerde metalen platen 55\% emissiereductie fijnstof (BWL 2007.09.V2).

\begin{tabular}{|c|c|c|c|c|c|c|c|c|c|c|c|c|c|c|c|}
\hline & Redur & ties & letir & & & & $\begin{array}{l}\text { Gem. } \\
\text { Red. }\end{array}$ & \begin{tabular}{|c|} 
Gem. \\
E > Red.
\end{tabular} & \begin{tabular}{|c|} 
Gem. $E_{(1,2,3)}$ \\
$>$ Red.
\end{tabular} & Var. & $\begin{array}{l}\text { SD } \\
\text { abs. }\end{array}$ & $\begin{array}{l}\text { SD } \\
\text { rel. }\end{array}$ & $\begin{array}{c}\text { SE } \\
\text { gem. }\end{array}$ & $\begin{array}{c}95 \%-B I \\
\text { gem. }\end{array}$ & \begin{tabular}{|l|} 
Geaccept. \\
onzekerh.
\end{tabular} \\
\hline Bedrijf 2 & 91 & 86 & 89 & 80 & 79 & 85 & 85.1 & - & - & 23.0 & 4.8 & 5.6 & 2.0 & $80-90$ & \pm 5 \\
\hline Bedrijf 1| $2(n=2)$ & & & & & & & 75.4 & - & - & 188.4 & 13.7 & 18.2 & 9.7 & $-48-199$ & \pm 123 \\
\hline Verschil B2 vs. B1 & & & & & & & 19.4 & & & & & & & & \\
\hline
\end{tabular}

Data afkomstig uit:

- Winkel et al. (2011), WLR Rapport 280: https://edepot.wur.nl/166949;

- Winkel et al. (2014), WLR Rapport 731: https://edepot.wur.nl/166949.

De onzekerheid van 123 procentpunten op het gemiddelde van 75.4 procentpunten reductie bedraagt relatief $163.6 \%$ Het verschil B2 vs. B1 van 19.4 op het gemiddelde van 75.4 procentpunten reductie bedraagt relatief $25.8 \%$.

Tabel 10 Gemeten reductiepercentages, gemiddelde reductiepercentages per bedrijfslocatie, het verschil tussen de bedrijfsgemiddelde reductiepercentages, het overall gemiddelde reductiepercentage en de onzekerheid rondom het overall gemiddelde reductiepercentage, uitgedrukt als 95\% betrouwbaarheidsinterval voor de techniek: E 1.9 chemisch luchtwassysteem 90\% ammoniakemissiereductie, $40 \%$ geuremissiereductie en 35\% fijnstofemissiereductie (BWL 2007.05.V7) voor opfokleghennen (E 1.9) alsook E $\mathbf{5 . 4}$ chemisch luchtwassysteem $\mathbf{9 0 \%}$ ammoniakemissiereductie, $40 \%$ geuremissiereductie en $35 \%$ fijnstofemissiereductie (BWL 2007.05.V7) voor vleeskuikens (E 5.4).

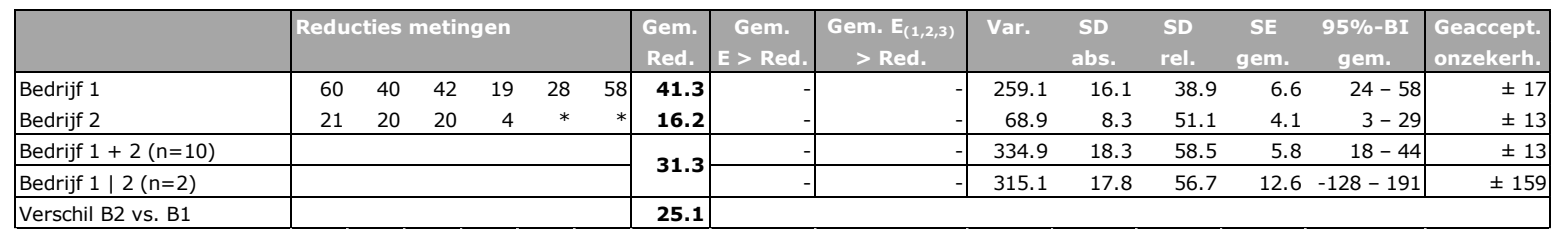

Data afkomstig uit Mosquera et al. (2011), WLR Rapport 295: https://edepot.wur.nl/163741.

De onzekerheid van 159 procentpunten op het gemiddelde van 31.3 procentpunten reductie bedraagt relatief $509.4 \%$. Het verschil B2 vs. B1 van 25.1 op het gemiddelde van 31.3 procentpunten reductie bedraagt relatief $80.2 \%$.

Tabel 11 Gemeten reductiepercentages, gemiddelde reductiepercentages per bedrijfslocatie, het verschil tussen de bedrijfsgemiddelde reductiepercentages, het overall gemiddelde reductiepercentage en de onzekerheid rondom het overall gemiddelde reductiepercentage, uitgedrukt als 95\% betrouwbaarheidsinterval voor de techniek: E 2.13 biologisch luchtwassysteem 70\% ammoniakemissiereductie, $\mathbf{4 5} \%$ geuremissiereductie en $\mathbf{6 0} \%$ fijnstofemissiereductie voor leghennen (E 2.13).

\begin{tabular}{|c|c|c|c|c|c|c|c|c|c|c|c|c|c|c|c|}
\hline & \multicolumn{6}{|c|}{ Reducties metingen } & \multirow{2}{*}{\begin{tabular}{|c|}
$\begin{array}{r}\text { Gem. } \\
\text { Red. }\end{array}$ \\
$\mathbf{4 8 . 9}$
\end{tabular}} & $\begin{array}{c}\text { Gem. } \\
\text { E > Red. }\end{array}$ & $\begin{array}{c}\text { Gem. } E_{(1,2,3)} \\
>\text { Red. }\end{array}$ & \multirow{2}{*}{$\begin{array}{l}\text { Var. } \\
11.1\end{array}$} & $\begin{array}{l}\text { SD } \\
\text { abs. }\end{array}$ & \multirow{2}{*}{$\begin{array}{l}\text { SD } \\
\text { rel. } \\
6.8\end{array}$} & \multirow{2}{*}{\begin{aligned} \multicolumn{1}{c}{$\mathrm{SE}$} \\
gem. \end{aligned}} & \multirow{2}{*}{$\begin{array}{c}\begin{array}{c}95 \%-B I \\
\text { gem. }\end{array} \\
45-53\end{array}$} & \multirow{2}{*}{\begin{tabular}{|r} 
Geaccept. \\
onzekerh.
\end{tabular}} \\
\hline Bedrijf 1 & 45 & 46 & 53 & 51 & 50 & * & & & & & 3.3 & & & & \\
\hline Bedrijf 2 & 46 & 66 & 67 & 75 & 65 & * & 64.0 & & & 114.6 & 10.7 & 16.7 & 4.8 & $51-77$ & \pm 13 \\
\hline Bedrijf $1+2+3(n=16)$ & & & & & & & \multirow{2}{*}{66.5} & & & 257.0 & 16.0 & 24.1 & 4.0 & $58-75$ & \pm 9 \\
\hline Bedrijf $1|2| 3(n=3)$ & & & & & & & & & & 298.3 & 17.3 & 26.0 & 10.0 & $24-109$ & \pm 43 \\
\hline Gemiddeld verschil & & & & & & & 23.0 & & & & & & & & \\
\hline
\end{tabular}

Data afkomstig uit Mosquera et al. (2011), WLR Rapport 295: https://edepot.wur.nl/163741.

De onzekerheid van 43 procentpunten op het gemiddelde van 66.5 procentpunten reductie bedraagt relatief $64.5 \%$.

Het gemiddelde verschil van 23 op het gemiddelde van 66.5 procentpunten reductie bedraagt relatief $34.5 \%$. 
Tabel 12 Overzicht van alle fijnstof reducerende technieken in de "Lijst Emissiefactoren fijnstof voor veehouderij", hun gemiddelde reductiepercentage en de breedte van het 95\%-

betrouwbaarheidsinterval in absolute reductieprocenten gebaseerd op de spreiding tussen bedrijfsgemiddelden.

\begin{tabular}{|l|c|cc|}
\hline Techniek & n & $\begin{array}{l}\text { Gem. } \\
\text { reductie } \\
(\%)\end{array}$ & $\begin{array}{l}95 \% \text {-BI } \\
\text { voor de gemiddelde } \\
\text { reductie in absolute } \\
\text { reductieprocenten }\end{array}$ \\
\hline (aem.) & & 55.0 & \pm 119 \\
\hline E 7.1 Oliefilmsysteem vleeskuikens & 2 & 49.1 & \pm 15 \\
E 7.2 Ionisatie neg. corondadraden vleesk. & 2 & 47.2 & \pm 202 \\
E 7.3 Waterluchtwassysteem & 2 & 40.1 & \pm 8 \\
E 7.4 Droogfilterwand & 2 & 68.1 & \pm 25 \\
E 7.5 Ionisatiefilters & 2 & 78.4 & \pm 130 \\
E 7.6 / 7.7 / 7.11 / 7.12 Warmtewisselaars & 5 & 21.8 & \pm 9 \\
E 7.10 Strooiselschuif in volièrehuisv. & 2 & 47.6 & \pm 136 \\
E 6.4.1 Droogtunnel met geperf. banden & 2 & 75.4 & \pm 123 \\
E 6.4.2 Droogtunnel met geperf. platen & 2 & 31.3 & \pm 159 \\
E 1.9 / E 5.4 Chemische luchtwasser 90\% red. NH3 & 3 & 66.5 & \pm 43 \\
E 2.13 Biologische luchtwasser 75\% red. NH3 & 2 & 49.1 & 119 \\
\hline Mediaan & & & \\
\hline
\end{tabular}

Tabel 13 Overzicht van alle fijnstof reducerende technieken in de "Lijst Emissiefactoren fijnstof voor veehouderij", hun gemiddelde reductiepercentage en het verschil tussen de bedrijfsgemiddelde reductiepercentages, alsook de overall mediaan daarvan.

\begin{tabular}{|c|c|c|c|c|c|}
\hline $\begin{array}{l}\text { Techniek met Rav-code 'Lijst Emissiefactoren } \\
\text {... Veehouderij' }\end{array}$ & $\begin{array}{l}\text { Plaats } \\
\text { techniek }\end{array}$ & $\begin{array}{l}\text { Fysisch } \\
\text { werkingsmechanisme }\end{array}$ & $\begin{array}{l}\text { (aantal } \\
\text { bedr. gem.) }\end{array}$ & $\left|\begin{array}{l}\text { Gem. } \\
\text { reductie } \\
(\%)\end{array}\right|$ & $\begin{array}{l}\text { Verschil } \\
\text { bedr. } 1 \text { vs. bedr. } 2 \\
\text { (verschil in "absolute" } \\
\text { reductieprocenten) }\end{array}$ \\
\hline E 7.1 Oliefilmsysteem vleeskuikens & Stal & Aggregatie/gravitatie/sedimentatie & 2 & 55.0 & 18.8 \\
\hline E 7.2 Ionisatie neg. corondadraden vleesk. & Stal & Elektrostatische precipitatie & 2 & 49.1 & 3.4 \\
\hline E 7.3 Waterluchtwassysteem & End-of-pipe & Inertiele impactie & 2 & 47.2 & 31.8 \\
\hline E 7.4 Droogfilterwand & End-of-pipe & Inertiele impactie & 2 & 40.1 & 2.2 \\
\hline E 7.5 Ionisatiefilters & End-of-pipe & Elektrostatische precipitatie & 2 & 68.1 & 3.9 \\
\hline E $7.6 / 7.7 / 7.11 / 7.12$ Warmtewisselaars & End-of-pipe & Inertiele impactie & 2 & 78.4 & 20.5 \\
\hline E 7.10 Strooiselschuif in volièrehuisv. & Stal & Verminderen bronmateriaal & 5 & 21.8 & 8.5 \\
\hline E 6.4.1 Droogtunnel met geperf. banden & End-of-pipe & Inertiele impactie & 2 & 47.6 & 21.4 \\
\hline E 6.4.2 Droogtunnel met geperf. platen & End-of-pipe & Inertiele impactie & 2 & 75.4 & 19.4 \\
\hline E 1.9 / E 5.4 Chemische luchtwasser $90 \%$ red. NH3 & End-of-pipe & Inertiele impactie & 2 & 31.3 & 25.1 \\
\hline E 2.13 Biologische luchtwasser $75 \%$ red. $\mathrm{NH} 3$ & End-of-pipe & Inertiele impactie & 3 & 66.5 & 23.0 \\
\hline Mediaan & & & 2 & 49.1 & 19.4 \\
\hline
\end{tabular}

Tabel 14 Overzicht van het gemiddelde tussenbedrijfsverschil per plaats van de techniek in het stalsysteem en per werkingsmechanisme van de techniek, beide als potentiele categorie voor verbijzondering van een hierboven berekende overall mediane reductiepercentage.

\begin{tabular}{|l|c|c|}
\hline Potentiele verbijzondering & $\begin{array}{l}\text { Aantal } \\
\text { technieken }\end{array}$ & Tussenbedriffsverschil \\
\hline Plaats van de techniek in het stalsysteem & 3 & 10.2 \\
\hline Stal & 8 & 18.4 \\
End-of-pipe & 1 & \\
\hline Werkingsmechanisme van de techniek & & 18.8 \\
Aggregatie/gravitatie/sedimentatie & 2 & 3.7 \\
Elektrostatische precipitatie & 7 & 20.5 \\
Inertiele impactie & 1 & 8.5 \\
Verminderen bronmateriaal & & \\
\hline
\end{tabular}




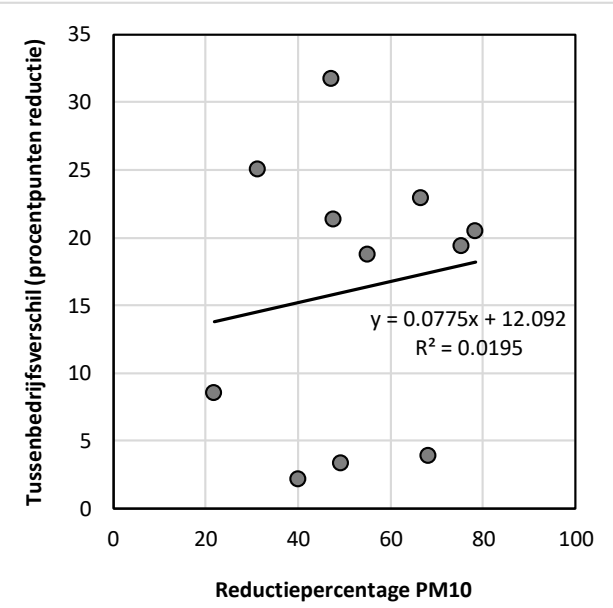

Figuur 2 Relatie tussen het tussenbedrijfsverschil van een techniek als functie van zijn gemiddelde reductiepercentage. De richtingscoëfficiënt is niet statistisch significant afwijkend van nul $(P=0,682)$.

\subsection{Toetsing bedrijfseffect op reductiepercentage techniek}

Het tweede doel van deze deskstudie is om vast te stellen of de prestaties van fijnstof reducerende technieken statistisch significant verschillen tussen de twee (soms 3 en 5 ) bedrijfslocaties per techniek.

Voor technieken die bemeten zijn op twee bedrijfslocaties is de toetsing uitgevoerd met de twosample $t$-test (éénzijdig getoetst bij $a=0,05$ ). De nulhypothese bij deze toetsing is dat de twee bedrijfsgemiddelden gelijk zijn. De $P$-waarde uit deze toets geeft de kans (tussen 0 en 1 ) dat deze hypothese waar is. Als deze kans kleiner is dan 0,05 (5\% kans), dan wordt deze verworpen. Er is dan statistisch significant aangetoond dat de prestatie van de techniek verschilt tussen de bedrijven. Voor technieken die bemeten zijn op meer dan twee bedrijfslocaties (vijf voor E 7.10 en drie voor E 2.13) is de toetsing vergelijkbaar uitgevoerd, maar dan met een One-way ANOVA. De nulhypothese bij deze toetsing is dat alle (drie dan wel vijf) bedrijfsgemiddelden gelijk zijn. Bij een $P$-waarde kleiner dan 0,05 is vervolgens getoetst wélke van de bedrijfsgemiddelden dan precies van elkaar verschillen.

De resultaten van de t-toetsen (negen technieken) worden weergegeven in tabel 15a. De resultaten van de ANOVA worden weergegeven in tabel $15 \mathrm{~b}$.

Uit de tabellen blijkt dat bij 7 van de 11 technieken statistisch significante verschillen worden gevonden in prestatie van de techniek tussen de bedrijfslocaties. Bij een achtste techniek (E 7.2, ionisatie met negatieve coronadraden) is er sprake van een statistische trendmatigheid: de $P$-waarde van 0,065 nadert daar de grens van significantie. Bij techniek E 7.10 (strooiselschuif) bestaat de dataset uit slechts 2 of 3 metingen per bedrijf waardoor het onderscheidend vermogen voor het aantonen van een eventueel aanwezig bedrijfseffect klein is (bijvoorbeeld tussen locatie 1 en 2 ). Voor techniek E 2.13 (biologische luchtwasser) valt op dat alle drie de bedrijfsgemiddelden statistisch significant van elkaar verschillen. Bij slechts twee technieken is er geen aanwijzing dat de bedrijfslocatie van invloed is op de prestatie van de techniek.

Voor elke techniek zijn specifieke redenen aan te geven waarom deze verschillend presteerde op verschillende bedrijfslocaties. Dat ligt echter buiten het doel van deze deskstudie. We stellen hier slechts vast dat vergelijkbare/identieke technische installaties, geïnstalleerd op verschillende bedrijfslocaties, bij de meerderheid van de technieken ( 7 van de 10) soms forse en statistisch significante verschillen in prestaties tussen de bedrijven laten zien. Voor emissiefactoren voor geur, ammoniak en fijnstof was al bekend dat de gemiddelde emissie van de ene bedrijfslocatie met een huisvestingssysteem flink kan afwijken van een volgende bedrijfslocatie met precies hetzelfde huisvestingssysteem (tussenbedrijfsvariatie; zie hoofdstuk 2). Dit speelt dus ook bij reductiepercentages van fijnstof reducerende reductietechnieken. 
Tabel 15a Overzicht van gemiddelde reductiepercentages voor bedrijfslocatie 1 en bedrijfslocatie 2 per techniek met de uitkomst van de $t$-toets op deze gemiddelden. De P-waarde in de laatste kolom geeft de kans weer (tussen 0 en 1) dat het verschil tussen de reductiepercentages aan toeval kan worden toegeschreven. P-waarden kleiner dan 0,05 (5\% kans) duiden op statistisch significant verschil. Dat wil zeggen: bij deze fijnstof reducerende technieken verschilt de prestatie van de techniek statistisch significant tussen de twee bedrijfslocaties.

\begin{tabular}{|l|r|r|r|r|r|}
\hline Techniek & \multicolumn{2}{|l|}{$\begin{array}{l}\text { Reductieperc. (\%) } \\
\text { Bedrijfs- }\end{array}$} & $\begin{array}{l}\text { Uitkomst } \\
\text { locatie } \text {-toets }\end{array}$ \\
& 71 & 50 & 21 & 8.6 & $\mathbf{0 . 0 2 1}$ \\
\hline E 7.1 Oliefilmsysteem vleeskuikens & Verschil & SE & P-waarde \\
\hline E 7.2 Ionisatie neg. corondadraden vleesk. & 35 & 58 & 22 & 13.5 & 0.065 \\
\hline E 7.3 Waterluchtwassysteem & 63 & 31 & 32 & 8.9 & $\mathbf{0 . 0 0 6}$ \\
E 7.4 Droogfilterwand & 41 & 39 & 1 & 6.6 & 0.428 \\
\hline E 7.5 Ionisatiefilters & 65 & 69 & 4 & 7.2 & 0.302 \\
\hline E 7.6 / 7.7 / 7.11 / 7.12 Warmtewisselaars & 89 & 68 & 21 & 8.6 & $\mathbf{0 . 0 1 9}$ \\
E 6.4.1 Droogtunnel met geperf. banden & 38 & 59 & 21 & 3.9 & $<\mathbf{0 . 0 0 1}$ \\
E 6.4.2 Droogtunnel met geperf. platen & 66 & 85 & 19 & 2.3 & $<\mathbf{0 . 0 0 1}$ \\
E 1.9 / E 5.4 Chemische luchtwasser 90\% red. NH3 & 41 & 16 & 25 & 8.8 & $\mathbf{0 . 0 1 1}$ \\
\hline
\end{tabular}

Tabel 15b Overzicht van gemiddelde reductiepercentages per techniek en per bedrijfslocatie met de uitkomsten van de One-way ANOVA. De P-waarde in de laatste kolom geeft de kans weer (tussen 0 en 1) dat tenminste één van de paartjes bedrijven verschillen in hun gemiddelde reductiepercentages. Met letters in superscript achter de reductiepercentages van de bedrijfslocaties is vervolgens aangeven welke bedrijven van elkaar verschillen.

\begin{tabular}{|c|c|c|}
\hline Techniek & $\begin{array}{l}\text { Uitkomst One- } \\
\text { Reductieperc. } \\
\text { *) }\end{array}$ & $\begin{array}{l}\text { ANOVA } \\
\text { vaarde }\end{array}$ \\
\hline E 7.10 Strooiselschuif in volièrehuisv. & & 0.884 \\
\hline - Bedrijfslocatie 1 & $33^{\mathrm{a}}$ & \\
\hline - Bedrijfslocatie 2 & $12^{\mathrm{a}}$ & \\
\hline - Bedrijfslocatie 3 & $23^{a}$ & \\
\hline - Bedrijfslocatie 4 & $23^{\mathrm{a}}$ & \\
\hline - Bedrijfslocatie 5 & $22^{\mathrm{a}}$ & \\
\hline E 2.13 Biologische luchtwasser $75 \%$ red. $\mathrm{NH} 3$ & & $<0.001$ \\
\hline - Bedrijfslocatie 1 & 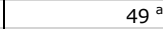 & \\
\hline - Bedrijfslocatie 2 & 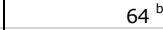 & \\
\hline - Bedrijfslocatie 3 & 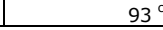 & \\
\hline
\end{tabular}

\subsection{Wenselijkheid meetcampagnes aan één bedrijfslocatie}

De analyses in paragraaf 4.3 laten zien dat wanneer een techniek zou worden beproefd bij een zeer groot aantal bedrijfslocaties er, binnen zekere grenzen, een variatie aan reductiepercentages rond een gemiddelde gevonden zal worden. Uit tabel 13, laatste kolom, blijkt dat het verschil in de reductie van een techniek tussen bedrijfslocaties kan variëren tussen 2 en 32 reductieprocenten. Het bemeten van slechts één bedrijfslocatie uit die verdeling is - populair gezegd - een "lucky (of unlucky) shot" en daarmee een onvoldoende betrouwbare/representatieve afspiegeling van de werkelijke gemiddelde prestatie van de techniek.

Door technieken te bemeten in één-bedrijf-meetcampagnes kunnen er o.a. twee situaties voorkomen: (1) de prestatie van de techniek op de bedrijfslocatie is (toevallig) één uit de onderkant van de verdeling. De techniek wordt ten onrecht beoordeeld als minder effectief dan gedacht. De kans bestaat dat een leverancier besluit om de agrarische markt te verlaten terwijl een "multi-site-approach" een accurater en gunstiger beeld had geschetst. En situatie (2): de prestatie van de techniek op de bedrijfslocatie is (toevallig) één uit de bovenkant van de verdeling. De techniek wordt ten onrechte beoordeeld als effectiever dan gedacht, of beter dan soortgelijke technieken met hetzelfde werkingsprincipe. De kans bestaat dat juist deze leverancier opteert voor opname op de Lijst waarbij het reductiepercentage dat in de Lijst wordt opgenomen een overschatting is van de werkelijke prestatie, zelfs bij aftrek van een onzekerheidsmarge van 10 absolute reductieprocenten. 
Om aan voornoemde problemen rond reductiepercentages uit één-bedrijf-meetcampagnes tegemoet te komen is het aftrekken van een kwantitatief onderbouwde veiligheidsmarge een mogelijkheid, maar wel een adhoc oplossing die als standaardprocedure naar het oordeel van de auteurs niet gewenst is; om twee redenen. In de eerste plaats is het bij deze oplossing niet duidelijk of het betreffende reductiepercentage afkomstig was uit de onderkant, het centrum of de bovenkant van de verdeling (zie hierboven); er is immers überhaupt geen tussenbedrijfsvariatie bekend. In de tweede plaats is het geen oplossing toegesneden op de werkelijke oorzaak van het probleem, namelijk het niet opnemen van meerdere bedrijfslocaties (en daarmee tussenbedrijfsvariatie) in de meetstrategie.

Desondanks hebben één-bedrijf-meetcampagnes zoals de fijnstofpilots in de Gelderse Vallei wel degelijk toegevoegde waarde, namelijk:

- het biedt de leverancier van een techniek de mogelijkheid om de agrarische markt te leren kennen;

- het biedt de leverancier van een techniek de mogelijkheid om zijn techniek verder te verbeteren en toe te spitsen op inzet binnen de setting van een stalgebouw en dierlijke productie. Dit is bijvoorbeeld mogelijk als een optimalisatiefase wordt gepland waarin allerlei aspecten/valkuilen kunnen worden beproefd en verbeterd;

- het bedrijf kan dienen als demobedrijf waar stakeholders de techniek in het echt werkzaam kunnen zien en de ervaringen van leverancier en gebruiker/veehouder kunnen vernemen;

- door de meetdata verkregen op de bedrijfslocatie wordt een goede eerste indruk verkregen van het perspectief van een techniek voor stalomgevingen;

- de leverancier hoeft niet direct twee bedrijfslocaties met een techniek uit te rusten waardoor de initiële investering beperkt blijft t.o.v. de multi-site-approach;

- de meetdata (mits verkregen volgens wetenschappelijk valide meetmethoden en meetstrategie) vormen een eerste stap naar een representatief en betrouwbaar reductiepercentage.

Samengevat hebben de fijnstofpilots in de Gelderse Vallei, en in het verlengde daarvan deze deskstudie, het inzicht opgeleverd dat dergelijke één-bedrijf-meetcampagnes t.a.v. verschillende aspecten een toegevoegde waarde kunnen hebben, maar tevens dat de multi-site-approach (2-4 bedrijfslocaties) - zoals die in de meetprotocollen van Nederland en VERA wordt voorgeschreven - het minimaal noodzakelijke is om een betrouwbaar en representatief reductiepercentage voor regelgeving te verkrijgen. Het gebruiken van de onzekerheidsmarge uit deze deskstudie zou naar het oordeel van de auteurs vanuit wetenschappelijk perspectief gezien moeten worden als tijdelijke maatregel; als tussenstap naar een eindcijfer. Aanbevolen wordt daarom om technieken die in één-bedrijfmeetcampagnes als perspectiefvol naar voren komen op tenminste een tweede bedrijfslocatie te bemeten.

\subsection{Tussenbedrijfsvariatie i.r.t. bedrijfsemissiemonitoring}

In het huidige toetsingskader ter bescherming van omwonenden van veehouderijbedrijven tegen te hoge concentraties fijnstof wordt gewerkt met standaard (forfaitaire/gemiddelde) emissiefactoren van huisvestingssystemen en standaard (forfaitaire/gemiddelde) reductiepercentages van technieken. Deze deskstudie heeft laten zien dat, net als bij emissiefactoren, de reductie van identieke installaties fors kan variëren tussen bedrijfslocaties. Dit betekent dat het gemiddelde reductiepercentage waarmee in het toetsingskader wordt gerekend, onzeker is: wellicht presteert de techniek op een specifiek bedrijf beter of slechter dan het gemiddelde. Mede vanwege deze nadelen van een toetsingskader op basis van vaste gemiddelden wordt er op dit moment op verschillende plaatsen gewerkt aan sensortechnologieën voor realtime bedrijfsemissiemonitoring voor veehouderijen.

Realtime monitoring van de prestatie van een emissie reducerende techniek biedt de mogelijkheid om de werking van de techniek beter te managen en te waarborgen. Het maakt in principe ook een andere manier van emissieregulering mogelijk door het huidige systeem van middelvoorschrift met generieke emissiefactoren om te zetten naar een doelvoorschrift met een bedrijfsspecifiek emissieplafond. 


\section{$5 \quad$ Conclusies en aanbevelingen}

Uit deze deskstudie o.b.v. datasets van in het verleden bemeten fijnstof reductietechnieken blijkt dat de onzekerheid die geaccepteerd wordt door reductiepercentages te baseren op meetseries aan twee bedrijfslocaties (twee installaties) in veel gevallen groot is. Uitgedrukt als 95\%betrouwbaarheidsinterval in absolute reductieprocenten varieert deze tussen het gemiddelde \pm 8 reductieprocenten en het gemiddelde \pm 202 reductieprocenten (mediaan: \pm 119 reductieprocenten; rekenkundig gemiddelde: \pm 88 reductieprocenten).

Verder is berekend welke extra onzekerheid in het reductiepercentage ontstaat wanneer een techniek (voorlopig) wordt bemeten bij één bedrijfslocatie. Deze onzekerheid kan benut worden om dergelijke technieken op te nemen in de officiële "Lijst Emissiefactoren fijnstof voor veehouderij" behorende bij de Regeling beoordeling luchtkwaliteit ( $\mathrm{Rbl}$ ) met een bijgesteld reductiepercentage bestaande uit de gemiddelde gemeten reductie minus een onzekerheidsmarge gelijk aan de berekende extra onzekerheid. Uit deze deskstudie wordt een algemene onzekerheidsmarge geadviseerd van 10 absolute procentpunten reductie. Op basis van de analyse van de datasets kan geen verbijzondering worden aangebracht naar aparte onzekerheidsmarges op grond van de plaats van de techniek in het stalsysteem (in de stal of end-of-pipe) of het werkingsprincipe van de techniek.

In de derde plaats blijkt uit voornoemde datasets dat vergelijkbare/identieke technische installaties, geïnstalleerd op verschillende bedrijfslocaties, bij de meerderheid van de technieken ( 7 van de 10) statistisch significante verschillen in prestaties tussen de bedrijven laten zien. Voor emissiefactoren voor geur, ammoniak en fijnstof was al bekend dat de gemiddelde emissie van de ene bedrijfslocatie met een huisvestingssysteem flink kan afwijken van een volgende bedrijfslocatie met precies hetzelfde huisvestingssysteem. Dit fenomeen treedt dus ook op bij reductiepercentages van fijnstof reducerende reductietechnieken.

Samengevat hebben de fijnstofpilots in de Gelderse Vallei, en in het verlengde daarvan deze deskstudie, het inzicht opgeleverd dat één-bedrijf-meetcampagnes t.a.v. verschillende aspecten een toegevoegde waarde kunnen hebben, maar tevens dat de multi-site-approach (2-4 bedrijfslocaties) zoals die in de meetprotocollen van Nederland en VERA wordt beschreven - het minimaal noodzakelijke is om een betrouwbaar en representatief reductiepercentage voor regelgeving te verkrijgen. Het gebruiken van de onzekerheidsmarge uit deze deskstudie zou naar het oordeel van de auteurs vanuit wetenschappelijk perspectief gezien moeten worden als tijdelijke maatregel; als tussenstap naar een eindcijfer. Aanbevolen wordt om technieken die perspectiefvol lijken uit éénbedrijf-meetcampagnes op tenminste een tweede bedrijfslocatie te bemeten. De ontwikkelingen rondom sensortechnologieën voor realtime bedrijfsemissiemonitoring bieden m.b.t. het voorgaande perspectief om de prestaties van emissiereducerende technieken vervolgens in de praktijk te managen en te waarborgen. 


\section{$6 \quad$ Literatuur}

Mosquera, J., J.M.G. Hol, \& N.W.M. Ogink. 2008. Analyse ammoniakemissieniveaus van praktijkbedrijven in de Varkenshouderij (1990-2003). Rapport 135. Lelystad: Animal Sciences Group, Wageningen University and Research Centre.

Ogink, N.W.M., J. Mosquera, \& J.M.G. Hol, 2013. Protocol voor meting van ammoniakemissie uit huisvestingssystemen in de veehouderij 2013. Rapport 726. Wageningen: Wageningen UR Livestock Research.

Ogink, N.W.M., C.M. Groenestein, \& J. Mosquera. 2014. Actualisering ammoniakemissiefactoren rundvee: advies voor aanpassing in de Regeling ammoniak en veehouderij. Rapport 744. Wageningen: Wageningen UR Livestock Research.

Ogink, N.W.M., P. Hofschreuder, \& A.J.A. Aarnink. 2011. Protocol voor meting van fijnstofemissie uit huisvestingssystemen in de veehouderij 2010. Report 492. Lelystad: Wageningen University and Research, Wageningen Livestock Research.

Ogink, N.W.M., C. ter Beek, \& J.V. Klarenbeek. 1997. Odor emission from traditional and low-emitting swine housing systems: emission levels and their accuracy. Conference paper, ASAE Annual International Meeting, Minneapolis, Minnesota, August 10-14, 1997.

Ogink, N.W.M., P.N. Lens. 2001. Geuremissies uit de veehouderij - Overzichtsrapportage 1996-1999. IMAG Rapport 2001-14. Wageningen: IMAG.

Rijksoverheid, 2019. Lijst Emissiefactoren fijn stof voor veehouderij. Online beschikbaar op: https://www.rijksoverheid.nl/documenten/publicaties/2018/03/15/emissiefactoren-fijn-stof-voorveehouderij-2018. Versie 15 maart 2018.

VERA, 2018a. VERA test protocol for air cleaning technologies. Version 2:2018-09. International secretariat, Verification of Environmental Technologies for Agricultural Production.

VERA, 2018b. VERA test protocol for housing and management systems. Version 3:2018-09. International secretariat, Verification of Environmental Technologies for Agricultural Production.

VROM, 1996. Beoordelingsrichtlijn emissie-arme stalsystemen. Uitgave maart 1996. Den Haag: Ministerie van Volkshuisvesting, Ruimtelijke Ordening en Milieu.

Winkel, A., J. Mosquera, P.W.G. Groot Koerkamp, N.W.M. Ogink, \& A.J.A. Aarnink. 2015. Emissions of particulate matter from animal houses in the Netherlands. Atmospheric Environment 111, p. 202212. 


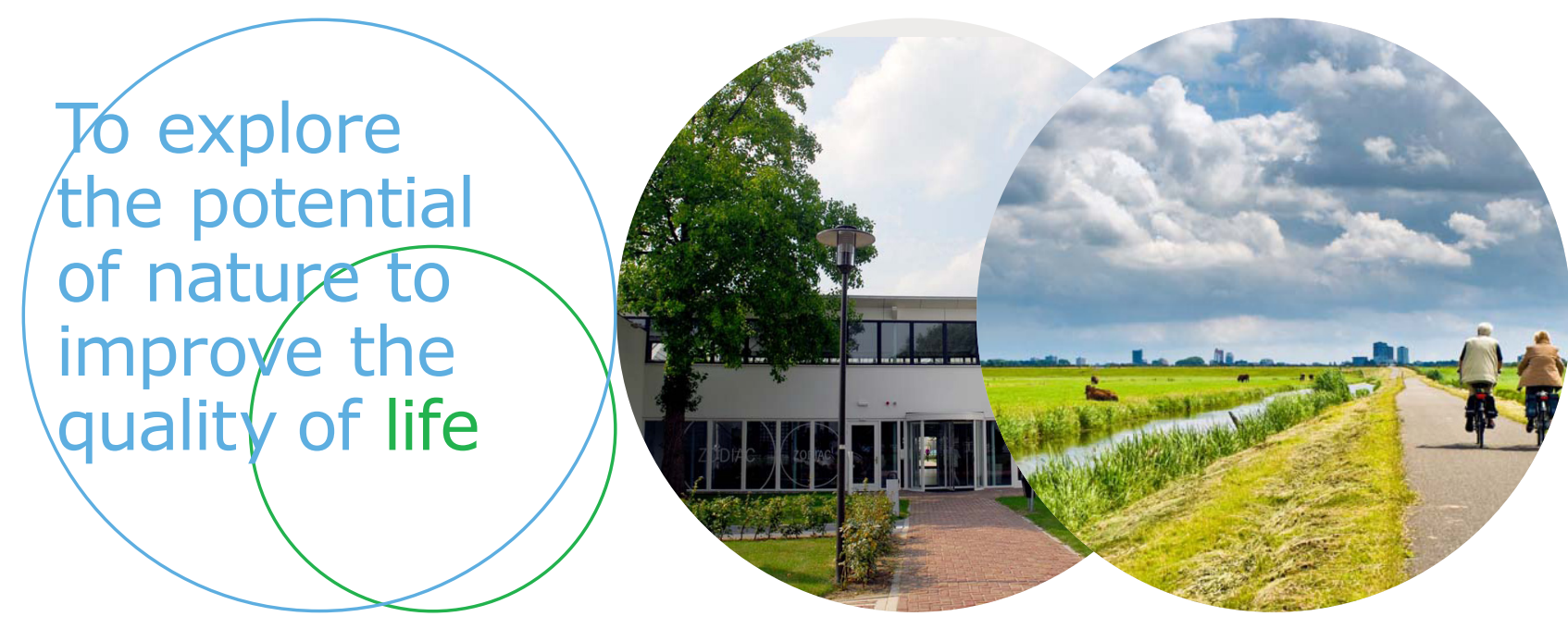

Wageningen Livestock Research Postbus 338

$6700 \mathrm{AH}$ Wageningen

T 0317483953

E info.livestockresearch@wur.nl www.wur.nl/livestock-research
Wageningen Livestock Research ontwikkelt kennis voor een zorgvuldige en renderende veehouderij, vertaalt deze naar praktijkgerichte oplossingen en innovaties, en zorgt voor doorstroming van deze kennis. Onze wetenschappelijke kennis op het gebied van veehouderijsystemen en van voeding, genetica, welzijn en milieu-impact van landbouwhuisdieren integreren we, samen met onze klanten, tot veehouderijconcepten voor de $21 \mathrm{e}$ eeuw.

De missie van Wageningen University \& Research is 'To explore the potential of nature to improve the quality of life'. Binnen Wageningen University \& Research bundelen 9 gespecialiseerde onderzoeksinstituten van Stichting Wageningen Research en Wageningen University hun krachten om bij te dragen aan de oplossing van belangrijke vragen in het domein van gezonde voeding en leefomgeving. Met ongeveer 30 vestigingen, 6.500 medewerkers en 10.000 studenten behoort Wageningen University \& Research wereldwijd tot de aansprekende kennisinstellingen binnen haar domein. De integrale benadering van de vraagstukken en de samenwerking tussen verschillende disciplines vormen het hart van de unieke Wageningen aanpak. 